\title{
HOW DOES CONSUMPTION RESPOND TO NEWS ABOUT INFLATION? FIELD EVIDENCE FROM A RANDOMIZED CONTROL TRIAL
}

\author{
Olivier Coibion \\ Dimitris Georgarakos \\ Yuriy Gorodnichenko \\ Maarten van Rooij \\ Working Paper 26106 \\ http://www.nber.org/papers/w26106
}
NATIONAL BUREAU OF ECONOMIC RESEARCH
1050 Massachusetts Avenue
Cambridge, MA 02138
July 2019

The views expressed in this paper are those of the authors and do not necessarily reflect the views of the European Central Bank, De Nederlandsche Bank, or the National Bureau of Economic Research.

NBER working papers are circulated for discussion and comment purposes. They have not been peer-reviewed or been subject to the review by the NBER Board of Directors that accompanies official NBER publications.

(C) 2019 by Olivier Coibion, Dimitris Georgarakos, Yuriy Gorodnichenko, and Maarten van Rooij. All rights reserved. Short sections of text, not to exceed two paragraphs, may be quoted without explicit permission provided that full credit, including () notice, is given to the source. 
How Does Consumption Respond to News about Inflation?

Field Evidence from a Randomized Control Trial

Olivier Coibion, Dimitris Georgarakos, Yuriy Gorodnichenko, and Maarten van Rooij

NBER Working Paper No. 26106

July 2019

JEL No. C83,D84,E31

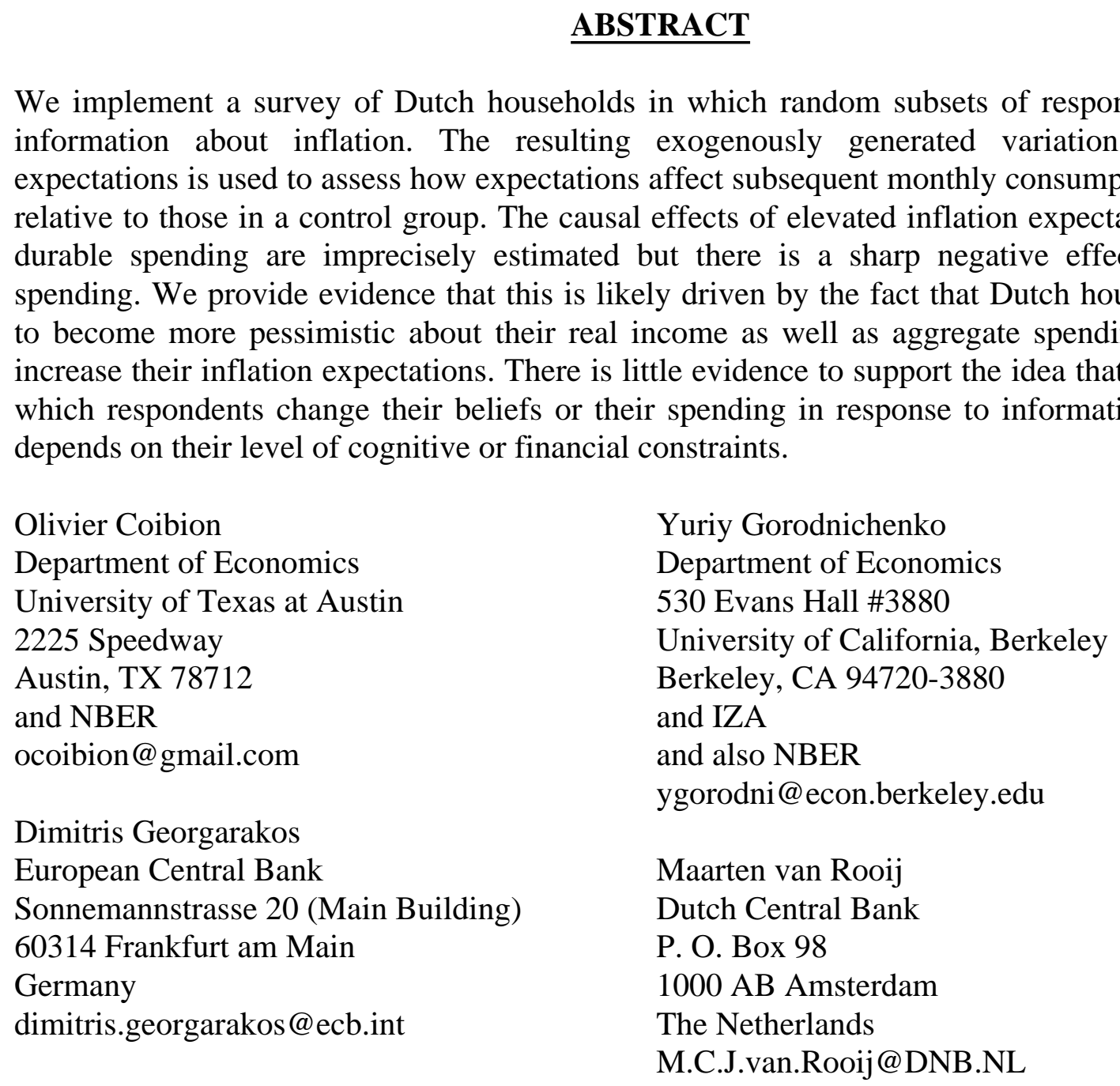




\section{Introduction}

As policy rates across advanced economies fell close to zero during and following the Great Recession, policy-makers sought out new tools to spur economic activity and inflation. Many of these tools were thought to operate in part through inflation expectations, and thereby real interest rates. While theory suggests that policies like forward guidance could have very large effects on consumption and other real economic variables, evidence from actual policy decisions suggests modest effects at best, a contrast often denoted as the forward guidance puzzle (Del Negro, Giannoni and Patterson 2015). Using a novel methodological strategy to study the spending behavior of households, we provide evidence for a new potential explanation to this puzzle.

This paper represents the first attempt to apply a randomized control trial (RCT) approach to determine how inflation expectations affect spending decisions of actual households in the economy. Specifically, we apply randomized information treatments about recent inflation to a representative sample of households in the Netherlands participating in a survey. These treatments lead to discernible and exogenously generated changes in the inflation expectations of the treated households relative to those in the (untreated) control group. Using follow-up surveys of these same households, we then determine whether these exogenous changes in inflation expectations affected the spending decisions of households in subsequent months. Given the fact that the treatment was implemented during the period in which the European Central Bank's policy rate was around the effective lower bound (ELB), our results speak directly to the effect of changes in inflation expectations on economic outcomes. We find that inflation expectations do affect spending decisions but not in the way that is commonly predicted in macroeconomic models.

Standard theory underlying the predicted effects of changes in inflation expectations focuses on a household's willingness to reallocate its consumption across different periods in light of the real interest rate, which captures the relative price of consumption across periods, and the discount rate, which captures how individuals compare utility across periods. When applied to non-durable goods consumption ${ }^{1}$, this framework yields the prediction that higher inflation expectations should lead to lower expected real interest rates at the zero bound, a lower return to saving, and a higher level of spending today. Consistent with this prediction, we find that spending

\footnotetext{
${ }^{1}$ We use the term non-durable goods throughout the paper to refer to the total of non-durable goods and services.
} 
on non-durable goods by Dutch households does seem to rise when they raise their inflation expectations, although the effects are too noisy to ascribe precise magnitudes.

However, we find that spending on durable goods falls sharply when these same households raise their inflation expectations. This occurs along both the intensive and extensive margins: households report a lower frequency of purchasing big-ticket items as well as smaller purchases when they have higher inflation expectations. The effect of this decline in durable goods purchases is large and dwarfs the change in non-durable spending. The result is that total spending by households declines when their inflation expectations are exogenously raised. The absence of a discretionary increase in spending on the part of households following an increase in their inflation expectations could therefore naturally account for the small observed effects of policies like forward guidance on macroeconomic outcomes.

Our approach is closely related to recent work focusing on the forward guidance puzzle. The most commonly emphasized source of the discrepancy is the consumption Euler equation, which implies that very distant changes in interest rates should have large effects on consumption. McKay, Nakamura and Steinsson (2016), for example, argue that incomplete markets imply heavier discounting in the Euler equation, thereby weakening the consumption response to announcements of future policy changes. Fahri and Werning (2018) instead emphasize limited higher-order thinking by agents, a feature which also dampens consumption responses to news. Angeletos and Lian (2018) stress imperfect common knowledge as a related mechanism. ${ }^{2}$

In contrast to these papers, we emphasize the importance of durable goods spending in explaining the total spending response of households when inflation expectations are revised. Nonetheless, our survey results also speak to these previously proposed mechanisms. This reflects the fact that respondents were asked questions that quantify both their cognitive and financial constraints, allowing us to directly test the first two types of channels. We find little support for either. Respondents who do higher orders of thinking do not raise their spending more than those with lower orders of thinking when they expect higher inflation, which is the mechanism operating in Fahri and Werning (2018). Nor do we find that financially constrained households raise their consumption less than unconstrained households when they expect higher inflation, which is the mechanism operating in McKay, Nakamura and Steinsson (2016). Instead, the large declines in

\footnotetext{
${ }^{2}$ Afrouzi and Yang (2019) also attempt to explain the forward guidance puzzle through information frictions but do so by considering rational inattention in price-setting decisions rather than focusing on consumption decisions.
} 
spending that we observe happen primarily for respondents with higher levels of cognitive ability as well as higher levels of wealth and financial liquidity.

What drives the reduced spending of these households when they raise their inflation expectations? We document that Dutch households seem to take a stagflationary view of inflation. Specifically, households do not predict increased nominal income after we elevate their inflation expectations, that is, households effectively predict their real incomes to fall. They also tend to anticipate reduced spending at the aggregate level and even anticipate that other households will become more pessimistic about aggregate spending. This stagflationary view of inflation by Dutch households - which is in line with survey evidence for other countries (e.g., Kamdar 2019, Coibion, Gorodnichenko and Ropele 2018) — can therefore explain why Dutch households choose to cut rather than increase their spending on durable goods.

Our results are related to several additional literatures. One is on how economic agents form their expectations. This work has documented statistically and economically significant departures from the null of full-information rational expectations for a range of agents in a number of different settings: e.g., U.S. professional forecasters and households (Coibion and Gorodnichenko 2012, 2015), European professional forecasters (Andrade and Le Bihan 2013), German households (Dräger and Nghiem 2018), and firms in New Zealand (Coibion, Gorodnichenko and Kumar 2018) and Italy (Coibion, Gorodnichenko and Ropele 2018). Our survey and experimental evidence supports these previous findings: households respond to publicly available information, which indicates that they don't have full-information, and do so like Bayesians, consistent with noisy information models for example. We also build on this literature by studying the higher-order beliefs of households, much like Coibion et al. (2018; henceforth CGKR) for firms.

A second literature focuses more specifically on how inflation expectations of households affect their propensity to spend. Using the Michigan Survey of Consumers, Bachmann, Berg and Sims (2015) found little evidence that U.S. households with higher inflation expectations had different perceptions of whether now was a good time to purchase big-ticket household items. A number of follow-up papers have found evidence more consistent with the idea that inflation expectations should affect consumption. For example, using inflation expectations from the New York Fed's Survey of Consumer Expectations, Crump et al. (2015) estimate a value of 0.8 for the intertemporal elasticity of substitution. Dräger and Nghiem (2018) find similar results for German 
households using a survey developed by the University of Hamburg. Ichiue and Nishiguchi (2013) find evidence consistent with the Euler equation using household survey data in Japan during the ZLB period. Pooling data from seventeen European countries, Duca, Kenny and Reuter (2018) also find that when households expect inflation to be higher, they report that they are more inclined to spend on consumer durables. ${ }^{3}$ Unfortunately, these papers lack exogenous variation in inflation expectations and can only report correlations. Only a few papers provide more direct causal evidence. D'Acunto, Hoang and Weber (2016), for example, examine how an anticipated change in the VAT in Germany affected the expectations and readiness to spend of German households. We contribute to this literature by generating clearly exogenous variation in the inflation expectations of households, which allows us to assess the causal effects of the latter on household decisions. Importantly, our experimental approach is applied to actual households in the Netherlands and therefore speaks directly to the effects of exogenously-generated changes in inflation expectations on the spending decisions of households. Moreover, unlike many previous studies using qualitative questions about the propensity to spend on big-ticket items, we measure non-durable and durable monthly consumption separately in subsequent waves following our baseline survey. While our results of weakly positive non-durable consumption responses to higher inflation expectations are consistent with much of this recent literature, the negative effects found for durable goods as well as overall spending are much more at odds with this body of evidence.

Our results also build on a growing literature studying higher-order beliefs, particularly for macroeconomic variables. Following Fahri and Werning (2018) in particular, we characterize the degree of higher-order thinking of different households in our survey as well as measure their higher-order beliefs about aggregate spending. This unique dimension of the survey allows us not just to assess the degree to which consumption responds to changes in beliefs but also some of the underlying mechanisms. We document a number of novel features from this survey of households' higher-order beliefs about inflation. First, there is generally a strong positive correlation between the first-order and higher-order beliefs of households. Second, cross-sectional means of the two are similar, but the dispersion in higher-order beliefs is somewhat smaller. Third, the degree of higher-order thinking varies significantly across households, but does not appear to be strongly

\footnotetext{
${ }^{3}$ Related work has studied how inflation expectations affect other decisions households face, for example the composition of their assets (Vellekoop and Wiederholt 2017).
} 
correlated with how they form or revise their higher-order beliefs about inflation. In this sense, our results confirm prior evidence on higher-order beliefs of firms documented in CGKR.

However, we find little evidence that differences in higher-order thinking matter for consumption decisions, which speaks to recent models in which limits to higher-order thinking play an important role in the transmission mechanism. For example, there are few differences in how households respond to information treatments with respect to their degree of higher-order thinking, which suggests that the latter is not a primary source of differences in beliefs across households. Whether the signal is viewed as a private or public one also does not seem to make a difference. In particular, some treated households were told that the information about inflation provided to them was publicly available, others were told that this information was being provided to selected participants in the survey (both of which are true statements). This had no discernible impact on the way in which households revised either their first or higher order beliefs. The absence of any significant difference between the two is not consistent with imperfect common knowledge playing a central role in the expectations formation process either.

From a methodological point of view, we contribute to a small but budding literature that uses RCTs to address macroeconomic questions. To the best of our knowledge, we are the first to do so in the context of household consumption decisions and their relation to macroeconomic expectations. Prior work has focused on how expectations affect firms' pricing decisions (Coibion, Gorodnichenko and Kumar 2018; CGKR 2018) or house price expectations (Armona, Fuster and Zafar forthcoming). RCTs allow for clearer exogenous variation and more precise statements about causality than traditional identification strategies used in macroeconomic analysis. Our results highlight the potential usefulness of this approach in identifying the role of different economic channels behind economic decisions like those of households.

In Section 2, we describe the survey of Dutch households that was used to measure expectations and outcomes. Section 3 discusses various household expectations measured by the survey. The information treatments are described in Section 4, along with how they were implemented as well as their effects on inflation expectations. Section 5 presents results on the causal effects of inflation expectations on spending decisions of households, while Section 6 discusses the possible channels underlying the spending responses. Section 7 concludes. 


\section{Survey Design}

We use data from the CentER Internet panel, which is sponsored by the Dutch National Bank (DNB) and maintained by CentERdata at Tilburg University. The members of the panel are recruited through face-to-face or telephone interviews. CentERdata provides respondents who are selected for participation in the panel but who do not have a computer with Internet access with the necessary equipment (for more details on the CentERdata panel, see Teppa and Vis 2012). The baseline survey is conducted annually and collects detailed information on a range of demographic and economic characteristics for a representative sample of Dutch-speaking households. The panel includes 2,187 adult respondents from 1,843 households. In addition to the baseline survey, respondents participate during the course of a year in special purpose surveys.

We designed such a special purpose survey providing random sub-groups of respondents with different information treatments about inflation and asking a number of questions (pre- and post-treatment) that are necessary for our analysis. We administered the special survey and the information experiment to every panel participant aged 18 and older in April 2018. Participants are invited to take the survey in the first week of each month. Those who do not respond receive a reminder invitation and can fill in the survey in the second week of the month. Given that the survey allows for contacting respondents at a high-frequency (i.e., monthly), we repeated (part of) the survey in May, June and July 2018 in order to track changes in expectations and behavior in the post-treatment period. All surveys are done online.

The specific questions asked in each wave are in Appendix B. The first wave collected a range of households' expectations, both about the aggregate economy and their own economic situation. It also included a randomized information treatment, which was followed by a few additional questions. Subsequent waves targeted the behavior and expectations of the same respondents to assess whether and how the information treatments affected their beliefs and outcomes relative to the untreated control group. We describe the treatments in detail in Section 4.

Descriptive statistics about respondents are provided in Table 1. The average respondent is 49 years old, and about half are women. Half of the respondents have either a college or vocational education degree. The average net monthly household income is approximately $€ 2,500$ with a net financial wealth of $€ 38,000$, although the variance across respondents is very large for both. Spending on durables is infrequent but large when it occurs, such that average spending on durables is twice that on non-durables. 
In addition to standard demographics, we collect information on various household characteristics that can help us better understand the workings of forward guidance and other tools based on the management of expectations. Specifically, we ask respondents to report how much money they had in their checking and savings accounts and in cash on the day before their last regular paycheck arrived (excluding fixed term deposits, stocks, bonds, mutual funds, or retirement accounts, etc.). As discussed in Kaplan and Violante (2014), hand-to-mouth (liquidity constrained) consumers do not carry liquid assets from period to period and thus, a hand-to-mouth consumer should have zero liquid wealth just before receiving a paycheck. To the extent that liquidity constraints may be important for the response to forward guidance (e.g., McKay, Nakamura and Steinsson 2016), we should observe heterogeneous responses in consumer spending for liquid and illiquid households. Table 1 reports three measures of liquid wealth just before receiving a paycheck: i) absolute amount in euro; ii) as a multiple of net monthly income; iii) as a multiple of monthly (average over the previous three months) spending on non-durable goods. The median amount is approximately $€ 2,000,0.88$ of net monthly income, and 5 times their monthly spending on non-durable goods. There is considerable variation in liquid wealth across households (e.g., the interquartile range of liquid wealth is $€ 11,800)$ and the distribution has a thick right tail. Approximately, six percent of households reported zero liquid wealth just before receiving a regular paycheck. Using high-frequency data generated by a financial aggregation and bill-paying computer/smartphone application, Gelman et al. (2016) report that approximately 20 percent of U.S. households have zero liquid wealth before receiving a regular paycheck. Kaplan and Violante (2014) report a similar magnitude for U.S. households in the Survey of Consumer Finances.

García-Schmidt and Woodford (2019) and Fahri and Werning (2018) suggest that constraints in cognitive reasoning can also influence the reaction of households to policy announcements. To quantify the importance of this potential channel, we construct two measures. First, we ask respondents to play a game as in Nagel (1995) which measures the ability of consumers to eliminate dominated strategies and thus allows us to quantify a level of reasoning for each respondent. We describe the game and the results in Section 3.3 below. Second, we ask three standard questions on financial literacy and take the count of correct responses as a measure of literacy. ${ }^{4}$ On average,

\footnotetext{
${ }^{4}$ The specific questions are:

a. "Suppose you had $€ 100$ in a savings account and the interest rate was $2 \%$ per year. After 5 years, how much do you think you would have in the account if you left the money to grow: more than $€ 102$, exactly $€ 102$, less than $€ 102$ ?"
} 
consumers get a score of 2 (out of 3 ) with 44 percent of respondents answering all question correctly and 16 percent of respondents answering all questions incorrectly. In their seminal work introducing this literacy scale, Lusardi and Mitchell (2011), report that 30 (12) percent of the adult US population answered all (no) questions correctly with an average of 1.8 (out of 3 ) correct answers.

\section{Unconditional Properties of Households' Expectations}

\subsection{Household Income and Spending on Durables and Non-Durables}

Respondents are asked a wide range of forward-looking questions, both about their own circumstances as well as their beliefs about aggregate economic conditions (translated survey questions from each wave are in Appendix B). For example, after being separately asked about the level of their spending on durable and non-durable goods over the previous three months, they are asked to provide point forecasts about how much they expect to spend on each over each of the following three months. This provides us with an anticipated level of monthly expenditures for each type of spending. Households are then asked, using a distributional question, to characterize the likely path of their household's spending on non-durables as well as their income over the next twelve months..$^{5}$ As documented in Table 2, respondents report that they expect their spending on non-durable goods to rise by $1.33 \%$ on average over the next twelve months. There is significant cross-sectional variation in this planned level of spending, however, with many reporting that they expect their spending to rise or fall by much more than this. Respondents report expected changes in their household net income which are very much in line: the average rise in expected income is also about $1 \%$ with a similar amount of cross-sectional dispersion as for spending. There is a weak positive correlation $(\rho=0.16)$ in individuals' expectations of their future income and spending on non-durables, which suggests respondents interpret most of their income changes as transitory.

Because the questions regarding twelve month ahead forecasts of non-durable spending and income are distributional, we can also measure the uncertainty associated with their forecasts.

\footnotetext{
b. "Imagine that the interest rate on your savings account was $1 \%$ per year and inflation was $2 \%$ per year. After 1 year, how much would you be able to buy with the money in this account: more than today; exactly the same, less than today?"

c. "Do you think that the following statement is 'true' or 'false'? Buying a company stock usually provides a safer return than a stock mutual fund."

${ }^{5}$ We fit generalized beta distributions to their reported distributions to measure mean and standard deviation of their forecasts.
} 
The average uncertainty of individuals with respect to these two economic variables is close to but somewhat smaller than the cross-sectional disagreement in each. Individuals who are more uncertain about their future income also tend to be more uncertain about their future non-durable spending, with a correlation of 0.55 .

An unusual feature of the survey is that respondents were asked not just about their own expected change in consumption but also about what they expected spending on non-durables to be for the whole economy over the next twelve months, again via a distributional question. As reported in Table 2, the average expectation of aggregate spending on non-durables is very close to the average expectation across individuals of planned changes in personal non-durable spending: $1.65 \%$ vs. $1.33 \%$ respectively. The dispersion in forecasts about aggregate non-durable spending is somewhat lower than that for individual spending, as is uncertainty about each. Individuals who anticipate larger increases in their spending generally anticipate higher spending at the aggregate level as well, with a correlation of 0.54 .

In addition to questions about expected aggregate spending, respondents were asked about what they thought other households expected would happen to aggregate non-durable spending, thereby measuring their higher-order belief about this variable. The average higher-order belief is almost identical to the first-order belief at $1.79 \%$ vs. $1.65 \%$ respectively, but the former is associated with significantly lower disagreement (cross-sectional standard deviation of 1.95 vs. 2.20 respectively) but somewhat higher uncertainty. There is again a strong positive correlation across beliefs: individuals who expect themselves to spend more over the next twelve months also tend to think that other households expect others to spend more, with a correlation of 0.41 .

\subsection{Inflation Expectations}

After being asked about spending and income, respondents were asked about aggregate prices. First, they were presented with a question asking about the percentage change in consumer prices over the last twelve months. The median response was $2.0 \%$, close to the actual rate of $1.2 \%$ in February 2018 (the most recent publicly available figure for inflation at the time of the first wave of the survey). At

the same time, there is a thick right tail in the distribution of perceived inflation so that the mean response was $4.9 \%$, with a cross-sectional dispersion of $10.0 \%$. Approximately, five percent of respondents perceive inflation to be greater than $20 \%$ with some respondents reporting $100 \%$ perceived inflation over the previous twelve months. Because these extreme perceptions appear to be 
outliers, we also compute moments robust to extreme observations: Huber-robust mean and standard deviation are $2.2 \%$ and $1.3 \%$ respectively. This level of disagreement about recent inflation is relatively low compared to other recent surveys of households. For example, Coibion, Gorodnichenko and Weber (2019) report that the Huber-robust standard deviation of perceived inflation for U.S. households during the same period is $2.6 \%$ with the median inflation perception of $3.0 \%$ (actual inflation was $2.3 \%$ ). The low level of disagreement about recent inflation as well as the fact that the median belief about recent inflation is so close to actual inflation suggests that Dutch households were relatively familiar with inflation dynamics compared to households in other countries.

Individuals were then presented with a distributional question about aggregate inflation over the next twelve months. The average forecast was just under $2 \%$, very close to the European Central Bank's inflation target. ${ }^{6}$ For comparison, the DNB was predicting inflation rates of $1.4 \%$ in 2018 and 2.3\% in 2019 for the Netherlands. In contrast, average inflation forecasts of households in the U.S. at the time were well above those of professionals (Coibion et al. 2018). Disagreement about expected inflation across households was also comparably low, with a cross-sectional standard deviation on the same order of magnitude as for aggregate spending. Individuals report even less uncertainty about inflation than for aggregate spending. Not surprisingly, there is a strong positive relationship between individuals' perceived rates of inflation and their predicted rates of inflation, with a (Huber-robust) correlation of 0.61, consistent with other evidence for households (e.g., Jonung 1981). ${ }^{7}$

Unconditionally, there is little correlation between an individual's perceived rate of inflation and their predicted change in either personal non-durable consumption or aggregate non-durable consumption (Huber-robust correlations are 0.09 and 0.14 respectively). At the same time, the correlation between (pre-treatment) expected inflation and expected spending is stronger (column (3) in Table 2): 0.25 for personal spending on non-durable goods and 0.37 for aggregate spending on non-durable goods. Interestingly, expected inflation is only weakly correlated (0.12) with expected personal net income. Uncertainty about expected inflation is strongly correlated with uncertainty about income and spending variables (column (6) in Table 2).

One approach to estimating the effects of inflation expectations hews closely to these correlations. For example, Bachmann, Berg and Sims (2015) consider whether individuals in the Michigan Survey of Consumers are more likely to report that now is a good time to purchase big

\footnotetext{
${ }^{6}$ Moments of expected inflation for various subgroups are presented in Appendix Table 1.

${ }^{7}$ Evidence for the Netherlands is reported in Christensen, van Els and van Rooij (2006).
} 
ticket items when they expect higher inflation and find little such correlation. Crump et al. (2015) regress expected changes in spending of households in the New York Fed's Survey of Consumer Expectations on their expected inflation to estimate the intertemporal elasticity of substitution. In contrast, we go beyond this correlational approach and employ information treatments to generate exogenous variation in inflation expectations to assess how these affect spending decisions.

\subsection{Higher-Order Thinking}

García-Schmidt and Woodford (2019) and Fahri and Werning (2018) among others emphasize that limited levels of reasoning may be an important determinant of weak consumption responses to changes in interest rates as economic agents may fail to appreciate the power of generalequilibrium effects. To explore whether the level of reasoning is related to the strength of consumer spending responses, we elicit respondents' level of thinking as well as their higher-order beliefs about consumer spending done by other Dutch households.

Following CGKR and the earlier experimental literature (e.g., Nagel 1995, Nagel and Duffy 1997, Camerer, Ho and Chong 2004), we ask households to participate in a "beauty contest" game. The specific survey question was:

Please choose a number from zero to 100.

We will take your number as well as the numbers chosen by other participants to calculate the average number. The winning number will be the number that is closest to two-thirds (2/3) of the average number.

The participant who filled in the winning number will receive 500 euro (if more participants have filled in the winning number, the 500 euro will be divided equally among the winners).

A $k^{\text {th }}$-level thinker provides the following guess $g(k)$ :

$$
g(k)=\left(\frac{2}{3}\right)^{k} \times 50
$$

As discussed in Nagel (1995) and subsequent literature, individuals with deeper levels of reasoning should do more rounds of eliminating dominated strategies and thus pick a lower value of $g(k)$. Panel A of Figure 1 reports the distribution of guesses, with red vertical lines indicating values of $k$, blue line indicating responses one would observe if individuals pick $\left(\frac{3}{2}\right)^{k} \times 50$ (that is, people use $(3 / 2)$ rather than $(2 / 3))$, and the green line indicating $\left(\frac{2}{3}\right) \times 100$. The average value of the reported guesses is 47 (standard deviation 22), which is a bit higher than the average reported in other experiments outside labs (e.g., Camerer 1997). 
Consistent with experimental evidence, we find lumps at the points that correspond to various levels of thinking $(50,33,22$, etc.) but the distribution is not perfectly concentrated at these points. Indeed, there is considerable variation outside these points and many individuals pick dominated responses (e.g., anything that is greater than 66 is a dominated response). Usually, these suboptimal responses are interpreted as level-0 thinking in the sense that this level would capture a group of people who do not eliminate dominated strategies by failing to understand the rules of the game. To differentiate this group from others, we classify a respondent as $k=0^{+}$if he or she reports a guess in the $(40,50]$ range and as $k=0$ if he or she reports a guess in the $(50,100]$ range. $k=1,2,3,4$ includes everybody who reported a number in $(30,40],(20,30],(10,20]$ and $(0,10]$ ranges, respectively.

Nearly 50 percent of respondents are classified as $k=0$ with another 15 percent classified as $k=0^{+}$(Table 3). We find that reported guesses differ by respondents' sociodemographic characteristics. For example, younger, more educated, more financially literate people tend to pick lower values for their guesses, which correspond to higher levels of thinking. Panel B of Figure 1 shows kernel density of guesses by age group: younger respondents have a higher mass of responses that correspond to $k=1$ and $k=2$.

In addition to eliciting a numerical response, we ask respondents to report their beliefs about the distribution of numbers they think other participants are choosing. Specifically, the $[0,100]$ interval is split into ten equally sizes bins (e.g., $[0,10),[10,20)$ and so on) and respondents are asked to assign a fraction of households who (they think) would provide a numerical response for each bin. This question informs us about whether a chosen numeric response is consistent with a respondent's belief about choices of other participants in the game. In other words, a person may pick 66 as his guess (a dominated strategy) because he believes that everybody else picks 100 .

Panel A of Table 3 reports the perceived distribution of others' guesses by level of thinking. We observe that none of the levels correctly conjectures the true distribution of types. Consistent with CGKR, a typical respondent believes that: $i$ ) many other respondents have the same level of thinking as the respondent; ii) there are many types of respondents in terms of level- $k$ thinking (including individuals with levels of thinking greater than the level of the respondent); iii) the quality of the perceived distribution about others' guesses does not improve discernably in the respondent's level of thinking.

While respondents may have wrong perceptions about others' guesses, the reported guesses 
may still be internally consistent: to win the prize, a respondent should report a guess of two-thirds of the believed average guess of other respondents. ${ }^{8}$ To test the consistency, we estimate the following specification:

$$
\text { Guess }_{i}^{\text {Own }}=b \times E_{i}\left[\text { Guess }^{\mathrm{HO}}\right]+\text { error }_{i}
$$

where Guess $_{i}^{\text {Own }}$ is the guess submitted by person $i, E_{i}\left[\operatorname{Guess}^{\mathrm{HO}}\right]$ is person $i$ 's average guess for others' guesses. We find (Panel B of Table 3 ) that the estimated $b$ is generally close to one for respondents with low $k$, close to $2 / 3$ for respondents with $k=1,2$, and falls well below $2 / 3$ for $k \geq 3$.

Consist with prevalence of $k=0$ and $k=0^{+}$types, we find relatively small differences between low-order expectations of spending and higher-order expectations of spending (Appendix Table 2). In agreement with theoretical predictions, cross-sectional dispersion of beliefs is smaller for higher-order expectations than for low-order expectations. At the same time, we fail to find more confidence (smaller standard deviation implied by reported distribution) in higher-order expectations than in low-order expectations. In summary, while we observe considerable heterogeneity in levels of reasoning, the properties of the responses appear to pose a puzzle for popular models of limited reasoning.

\section{Effects of Information Treatments on Expectations}

After answering baseline questions, participants in the first wave of the survey were randomly assigned to one of three groups. One group was provided with the following statement:

"Before we proceed, we would like to share the following information with you. In a public release available to all Dutchmen at no charge, the Dutch Statistical Office recently reported that the percent increase in consumer prices in February compared to 12 months earlier in the Netherlands was 1.2\%".

The statement provides information about the most recent inflation rate and describes it as something that is publicly available to all citizens. The second group was provided with the following statement:

"Before we proceed, we would like to share the following information only with you and a few other households. The Dutch Statistical Office recently reported that the percent

\footnotetext{
${ }^{8}$ It may be the case that when asked directly about other households, survey participants will engage in an additional level of reasoning that was not present when they formed their own guess or expectation.
} 
increase in consumer prices compared in February to 12 months earlier in the Netherlands was $1.2 \%$ "

This alternative statement provides the same information about recent inflation but is phrased in such a way that individuals should view this as information which is privately provided to them. We therefore refer to the first group $(\mathrm{N}=702)$ as having been treated with a public signal while the second group $(\mathrm{N}=744)$ was treated with a private signal. The third group $(\mathrm{N}=741)$ receives no such information and serves as a control group.

To assess whether respondents believe that the provided information is widely known, those in the treatment groups were immediately asked what fraction of Dutchmen they thought knew the provided information. The average fractions were 18.4\% (standard deviation 18.9\%) for the private treatment group and $17.9 \%$ (standard deviation 18.2\%) for the public treatment group. Hence, the phrasing of the treatment did not lead respondents to interpret the information very differently in terms of how well known it was to other households.

Following these information treatments (or lack thereof for the control group), respondents were asked a number of follow-up questions. These questions covered their expectations about inflation, expected income and non-durable consumption over the next twelve months and expected aggregate consumption in the Netherlands over the next twelve months. To avoid asking respondents the same question twice, follow-up questions were phrased as point estimates rather than distributional questions.

We first characterize the average effects of information treatments on inflation expectations of respondents. To do so, we regress the change in individual inflation expectations in each wave relative to their pre-treatment belief on separate dummy variables equal to one if participants were treated with the public or the private signal, respectively. ${ }^{9}$ The resulting coefficients on each dummy variable tell us the average effect of each treatment on individual inflation expectations relative to the control group. We use Huber-robust regressions to systematically control for outliers in the data.

Because average inflation expectations are close to actual inflation (Table 2), regressing revisions in expectations on a treatment dummy variable may yield no materially important treatment effect, but this need not indicate that agents are not responding to the information. What one should expect to see, if respondents are responding to treatments as Bayesians, is that all agents

\footnotetext{
${ }^{9}$ Note that since inflation expectations in subsequent waves were measured in both distributional and point forecast versions, we can use both to assess how expectations respond over time. The prior belief is measured using the elicited distributional inflation forecast from wave 1 asked prior to information treatments.
} 
should place some weight on their priors and some weight on the signal, leading to convergence in beliefs. We illustrate this point in Figure 2. For the control group and each treatment group separately, we present scatter plots of agents' posterior beliefs (immediately after treatment) versus their prior beliefs about inflation. Panel A, for example, illustrates that the slope of the relationship is less than one even for the control group, reflecting the different nature of the inflation expectation questions asked (i.e., distributional vs. point forecasts) and possibly some mean reversion in the responses. Panels B and C show much flatter slopes for the treatment groups, suggesting that individuals in these groups placed less weight on their prior beliefs as they placed weight on the common signals they received.

To assess this prediction more formally and across waves, we regress individuals' posterior expectations $\left(E_{i}^{\text {post }} \pi_{t+1}\right)$ on their priors $\left(E_{i}^{\text {prior }} \pi_{t+1}\right)$, a dummy variable for being treated Treat $_{i}^{\text {Pub }}$ for the "public" information treatment and Treat ${ }_{i}^{\text {Pri }}$ for the "private" information treatment), and the interaction of the two:

$$
\begin{aligned}
E_{i}^{\text {post }} \pi_{t+1} & =b_{0}+b_{1} \times E_{i}^{\text {prior }} \pi_{t+1}+b_{2} \times E_{i}^{\text {prior }} \pi_{t+1} \times \text { Treat }_{i}^{\text {Pub }}+b_{3} \times \text { Treat }_{i}^{\text {Pub }} \\
& +b_{4} \times E_{i}^{\text {prior }} \pi_{t+1} \times \text { Treat }_{i}^{\text {Pri }}+b_{5} \times \text { Treat }_{i}^{\text {Pri }}+\text { error }_{i} .
\end{aligned}
$$

Given that the control group is not receiving any information, we would expect to see non-treated respondents place a higher weight on their priors than those in the treatment groups, so the interaction term should be negative. We report estimates of this regression across waves in Table 4. Panel A shows that "private information" and "public information" treatments have broadly similar effects. Consistent with Figure 2, we find that contemporaneously, individuals in the treatment groups place significantly less weight on their priors than do those in the control group. These effects on expectations dissipate rapidly: the average effects on beliefs have fully dissipated within one month of the treatment, irrespective of which measure of expectations we use (point or distribution).

Panel B of Table 4 shows the results of estimating the pooled treatment effect based on the following specification:

$$
E_{i}^{\text {post }} \pi_{t+1}=b_{0}+b_{1} \times E_{i}^{\text {prior }} \pi_{t+1}+b_{2} \times E_{i}^{\text {prior }} \pi_{t+1} \times \text { Treat }_{i}+b_{3} \times \text { Treat }_{i}+\text { error }_{i} .
$$

We find that little predictive power of the treatments is lost when we pool across treatments: $\mathrm{R}^{2}$ is similar for specifications with either pooled or separate treatments. When we pool across 
treatments, the implied weight on the prior falls from 0.54 for the control group to 0.35 for the treatment group. This is consistent with agents' forecasts in the treatment group converging toward the signal received. However, in subsequent waves, there are few differences in the weights assigned to prior beliefs between the treatment and control groups, confirming that the information about recent inflation in the treatments has no discernible long-lived effect on inflation expectations of Dutch households.

In short, we find that the information treatments have clear, albeit small and transient, effects on the inflation expectations of Dutch households. Although there is some heterogeneity in the strength of the response, households revise their inflation expectations toward the treatment that they receive, if any, in much the same way as documented in other information experiments on households and firms. However, given that Dutch households were initially better informed about inflation than commonly found in other advanced economies, the resulting average revisions in expectations were smaller than found in prior work. This suggests that the information treatments can serve as a valid source of exogenous variation in inflation expectations to study their causal effect on spending decisions of households.

\section{Effects of Expectations on Household Spending}

Inflation expectations are a frequent topic of discussion for policy-makers because, ultimately, they are perceived as affecting economic decisions. One channel through which these expectations may matter is the saving/spending decisions of households, as illustrated in e.g., the consumption Euler equation. But causal evidence on this channel remains limited due to the inherently endogenous nature of expectations and spending decisions. In this section, we overcome this issue by using the information treatments to identify exogenous variation in inflation expectations to characterize the effect of expectations on spending decisions.

Our approach stems from the fact that we observe ex-post spending on non-durables and durables on the part of households, measured in follow-up surveys, as well as exogenous variation in inflation expectations. To characterize the link between the two, we therefore rely on an instrumental variable (IV) strategy in which the treatments are used to identify exogenous variation in expectations. 
For non-durable spending, we regress ex-post non-durable expenditures (measured in waves 2-4) on post-treatment inflation expectations from wave 1. The econometric specification is given by the following equation:

$S_{i, t+h}^{c a t}=\alpha+\beta \times F_{i, t} \pi_{t+12}+\gamma \times F_{i, t-} S_{i, t+h}^{c a t}+\delta \times F_{i, t-} \pi_{t+12}+\theta \times \boldsymbol{X}_{i, t}+$ error $_{i, t+h}$

where $S_{i, t+h}^{c a t}$ denotes spending in category cat (non-durable/ durable) by household $i$ in month $t+h$ reported in survey at time $t+h ; F_{i, t} \pi_{t+12}$ is the 12-month ahead inflation forecast of household $i$ at the end of wave 1 (time $t$ ) after treatments while $F_{i, t-} \pi_{t+12}$ is the equivalent forecast prior to the treatment (time $t-$ ); $F_{i, t-} S_{i, t+h}^{c a t}$ is the prediction prior to the treatment of household $i$ in wave 1 (time $t-)$ of what the level of spending on goods in category cat would be at time $t+h$; and $\boldsymbol{X}_{i, t}$ is a vector of household controls. ${ }^{10}$ Note that the latter is measured prior to the information treatment and should capture much of the relevant information available to household $i$ at time $t$ about what own spending would be at time $t+h$. We instrument for the inflation expectations using a treatment dummy and the interaction of the treatment with households' prior inflation expectation. As documented in Table 5, the F-statistic for the first stage is generally higher than 10, indicating that the instruments are sufficiently strong for inference. ${ }^{11}$

We run these regressions for each individual post-treatment wave (columns (1)-(3)) as well as pooled across waves (column (4)) and present the results for spending on non-durables in Panel A of Table 5. In the first two months, the estimated effect on consumption is positive but insignificantly different from zero. In the third month, we detect a large positive effect, such that

10 The list of controls includes quadratic polynomial in age, log annual gross income, indicator variables for educational attainment and marital status.

${ }^{11}$ Because of significant noise in both expectations and consumption data, we use the following approach to minimize the effect of outliers. In the first stage, we use the Huber-robust regression to identify influential observations. In the process of running Huber-robust regressions, we generate a weight $\omega$ that quantifies the influence of each observation. In this step, Huber-robust regressions effectively eliminate (i.e., assign weight $\omega=0$ ) observations with extreme predictions for future inflation (e.g., 100 percent inflation in the next 12 months). In the second stage, we use jackknife to identify influential observations. That is, we run IV regressions (which use weights $\omega$ ) by dropping one observation at a time and recording the resulting coefficient $\beta$. We identify observation $i$ as influential if it moves $\beta$ by a magnitude greater than a certain threshold. To ensure that we apply the same threshold across specifications, we normalize estimated $\beta$ s by the standard error of $\beta$ estimated on the full sample. Belsley, Kuh and Welsch $(1980$, p. 28) identify influential observations as those that move the coefficient of interest by more than $2 / \sqrt{\# \text { obs }}$ (given the number of observations per wave, this would mean that the threshold is approximately 0.05 ), but it is also common practice to use a threshold of 1 (Bollen and Jackman 1990, p. 267). We use a threshold of 0.1 for specifications estimated on a single wave and 0.05 for specifications estimated on data pooled across waves. These thresholds eliminate less than 1 percent of the sample. 
the average effect across the three months is positive and statistically significant at the 10 percent level. The implied magnitude is large: a 1 percent exogenous increase in inflation expectations leads to an almost 10 percent increase in non-durable spending on average, in the three months following our experiment. However, the standard errors are very large and we cannot reject the null of much smaller effects. We interpret this result as a reflection of the significant noise in selfreported data on non-durable spending and the relatively small number of participants in the survey. In addition, the results suggest that the effects on non-durable goods spending may be delayed for some months, and we may be missing the brunt of the effects given that we only followed up with households for three months.

We then turn to the effects of inflation expectations on durable goods spending. To do so, we rely on two sets of questions in the survey. First, respondents were asked in wave 1 whether they planned to engage in any purchases of durable goods (including, for instance, cars, electronics, kitchen appliances, furniture, house maintenance and jewelries). If they answered yes, they were then asked about how much they expected to spend on these items. In follow-up waves, all respondents were asked whether they had made any purchases of durable goods over the previous month and if so, how much they had spent. These questions therefore provide us with both an extensive margin of durable goods spending (did they make unplanned purchases) as well as an intensive margin of durable goods spending (how much more or less did they spend than expected).

We first consider the extensive margin of durable goods spending. To do so, we use the same empirical specification as for non-durable goods spending but replace the dependent variable with a dummy variable equal to one if they did a durable goods purchase in that month. We also replace the ex-ante forecast of their spending with a dummy variable for whether they had initially planned to do a durable good purchase that month. Applying the same IV strategy as before for inflation expectations yields estimated values of $\beta$ shown in Panel B of Table 5 for each followup wave as well as pooled across all three follow-up waves. For each month, we find negative effects of inflation expectations on the probability of purchasing durable goods that month. The effects are economically large: a 1 percentage point exogenous increase in inflation expectations reduces the probability of purchasing durable goods by 25 percentage points on average. Unlike the estimated effects on non-durable goods, the estimated effects on the probability of purchasing durable goods are fairly precise and consistently imply large elasticities with respect to inflation expectations. However, given that we have follow-up surveys only over the next three months, we 
cannot determine whether households are simply delaying these purchases or whether they are cancelling them outright for the foreseeable future.

To assess the effect on the intensive margin of durable goods spending, we restrict our attention to households who purchased durable goods in one of the three follow-up waves. Because large durable goods purchases are infrequent, only 329 such responses are present in the three followup waves combined. As a result, we pool across all three waves using the log of their spending on durables as the dependent variable. Results, shown in Panel C of Table 5, suggest a negative effect on the amount spent on durable goods conditional on buying a durable good: a 1 percentage point exogenous increase in inflation expectations is followed by households spending around 60 percent less on these goods than they had originally planned, although this estimate is quite imprecise. We interpret this result as indicating that inflation expectations matter along the intensive margin as well, but there is insufficient variation in the data to speak clearly about the magnitude of the effects.

We can also combine the intensive and extensive margins to assess the total effect of inflation expectations on durable goods expenditures. In this case, we use a Tobit IV regression where the dependent variable is the log of (one plus) durable goods spending (Panel D, Table 5). The effects of higher inflation expectations are again negative and significant. They also appear to grow over time, indicating that the effects on durable goods may take significant time to be fully realized.

Finally, we consider the effect of changes in inflation expectations on the total level of household spending, defined as the sum of their spending on non-durables with their spending on durable goods items. We present results across each wave as well as pooled across the three followup waves (Panel E, Table 5). We find that total spending is lower on average, but the imprecision of the estimates remains high and we can only reject (at 10\% level of confidence) the null of no change when pooling across waves. This suggests that the decline in durable goods spending at least offsets, and may even dominate, the increase in non-durable good spending identified in Panel A.

These results do not hinge on using ex-post reported spending of households. We can verify this using the fact that households were asked to report their monthly spending plans in each of the follow-up waves. We can therefore examine if the reaction of spending plans to information treatments is similar to the reaction of actual consumer spending. In particular, we estimate the following version of equation (2):

$$
P_{i, w, t+h}^{c a t}=\alpha+\beta \times F_{i, t} \pi_{t+12}+\gamma \times F_{i, t-} S_{i, t+h}^{c a t}+\delta \times F_{i, t-} \pi_{t+12}+\theta \times X_{i, t}+\text { error }_{i, t+h}\left(2^{\prime}\right)
$$


where $P_{i, w, t+h}^{c a t}$ is spending for goods in category cat planned in wave $w$. We focus on the responses in the second wave of the survey since it gives us the largest number of observations (plans for spending in May and June) and it is closest to the treatment in the first wave of the survey. To maximize statistical power, we pool responses for planned spending in May and June. We find (column (5) of Table 5) that the estimated responses of planned spending, as expressed in these follow-up waves, are generally similar to the estimated responses of actual spending (column (4) of Table 5), although there is considerable sampling uncertainty in the estimates. This helps confirm that the identified responses of each type of consumption are not an anomaly: they are reflected both in ex-post reports of actual spending as well as ex-ante predictions for the path of that spending.

It also provides a potential rationale for why transitory changes in expectations in general and inflation expectation in particular can appear to have longer-lived effects on actions. The temporary effect on inflation expectations is itself not surprising and in fact consistent with earlier RCT studies for the U.S. and other countries (e.g., Cavallo, Cruces, and Perez-Truglia 2017, Coibion, Gorodnichenko and Weber 2019, Coibion, Gorodnichenko and Ropele 2018). If economic agents revise their plans for spending and other choices at the time of the treatment and then stick to these

plans even after treatment effects on inflation expectations are worn out, then one would expect to find results like those above. Indeed, Chetty and Szeidl (2007) document that some types of consumer spending may be rather inflexible and households may cut spending on food (more generally small purchases) in response to large negative income shocks to stick to their consumption plans. Our result that plans for spending react to transitory shocks is consistent with this type of effect.

\section{Channels}

We find robust evidence that inflation expectations affect spending on the part of households. While the evidence on non-durable spending is imprecise, the estimated effects on durable goods spending are much sharper and negative. How does one interpret these effects of inflation expectations on consumer spending? In this section, we explore several potential channels for how information treatments influence consumption choices of Dutch households.

\subsection{Expectations of other variables}

One interpretation of the observed spending responses on durable goods is that they reflect changing expectations of durable goods prices. Durable goods purchases depend not just on the 
perceived real interest rate but also on the expected path of prices of durable goods (e.g., consumers may expect a fall in the price of durables and thus they postpone purchases on durable goods until prices become more attractive). We do not observe price expectations for durable goods in the survey and so it is difficult for us to speak directly to this channel.

A second interpretation is that changes in inflation expectations also affect other expectations of households and those then lead to offsetting effects on spending patterns. Coibion, Gorodnichenko and Ropele (2018), for example, find that firms in Italy interpret higher inflation as associated with worse economic outcomes, both at the aggregate level and at the level of their firm, which may explain why firms with exogenously higher inflation expectations choose to reduce their employment in a persistent fashion.

To assess this possibility, we continue to use the same IV strategy as with ex-post spending outcomes of households but instead replace the dependent variable with their expectations about their future spending, their future nominal income, aggregate future spending on non-durables, or what they think other households expect about future non-durable spending. These expectations are from wave 1 immediately after the information treatment (if any) was applied to households. We replace the ex-ante expectation of future spending on the right-hand side with the ex-ante belief about the dependent variable measured prior to the treatment. We then instrument for posttreatment inflation expectations in the same way as before. Formally, we estimate the following specification

$$
\begin{aligned}
E_{i}^{\text {post }} X_{t+1} & =b_{0}+b_{1} \times E_{i}^{\text {post }} \pi_{t+1}+b_{2} \times E_{i}^{\text {prior }} \pi_{t+1}+b_{3} \times E_{i}^{\text {prior }} X_{t+1}+ \\
& + \text { controls }+ \text { error }_{i} .
\end{aligned}
$$

where $E_{i}^{\text {post }} X_{t+1}$ is the post-treatment expectation for the variable of interest $X, E_{i}^{\text {prior }} X_{t+1}$ is the pretreatment expectation for $X$, controls include, as before, quadratic polynomial in a respondent's age, indicator variables for a respondent's educational attainment, log gross annual income of the household, and an indicator variable for marital status. The key coefficient in this regression is $b_{1}$. The first-stage regression for $E_{i}^{\text {post }} \pi_{t+1}$ is given by equation (1'). The results are presented in Table 6 .

Households expect no change in their net nominal household income (column (1), Panel A) when their inflation expectations exogenously increase, meaning that their perceived real income declines. Consistent with this, they predict a strong decline in their spending on non- 
durable goods (column (2), Panel A): a one percent increase in inflation expectations leads to a 2.4 percent decrease in anticipated spending on non-durables. The reaction of households' expectations for aggregate spending on non-durables (column (3), Panel A) and households' higher-order expectations for aggregate spending on non-durables (column (4), Panel A) are similarly strong, indicating that they perceive that broader economic activity will be weaker. While counterintuitive for standard economic theory, these negative revisions in anticipated spending to elevated inflation expectations are consistent with correlations observed for U.S. households. Specifically, Kamdar (2019) documents that households in the Michigan Survey of Consumers and in the New York Fed's Survey of Consumer Expectations associate high inflation with high unemployment. In other words, U.S. and Dutch consumers apparently subscribe to a stagflationary view of inflation, even though inflation and unemployment have largely been negatively correlated in the data since the 1970s. Kamdar (2019) uses rational inattention to explain this apparent contradiction. Intuitively, if consumers can have only a limited number of signals about shocks hitting the economy, they will focus on the shocks that shift the Phillips curve because these shocks are costliest for welfare. As a result, even if inflation and unemployment are uncorrelated in the data generating process, inattentive consumers end up with a positive correlation between these variables because they concentrate on specific shocks.

Panels B and C in Table 6 report the reaction of net household income expectations in waves 2 through 4 to post-treatment inflation expectations immediately after the treatment. Panel B of the table shows that mean income expectations implied by the reported distribution generally continue to show little response to changes in inflation expectations. In contrast, uncertainty about income expectations (Panel C) declines. These responses suggest that uncertainty is unlikely to be a central channel of expected declines in future spending on non-durable goods (Table 6) or actual declines in spending on durable goods (Table 5).

Jointly, these results provide a possible interpretation for why total spending as well as spending on durables falls sharply when inflation expectations rise while non-durable spending, if anything, rises. The decline in expected real income calls for a decrease in total spending, particularly if the decline in income is perceived to be persistent. Because income is contemporaneously unchanged, meeting this necessary decline in total spending can be most easily accomplished by delaying and reducing durable goods purchases. The anticipated rise in prices is also likely to lead to some stocking up of storable goods, as documented elsewhere in D'Acunto, 
Hoang and Weber (2018) and Coibion, Gorodnichenko and Koustas (2017), which can explain why there may be an increase in non-durable goods spending while also pushing toward an additional reduction in durable goods spending to finance this stocking up behavior.

\subsection{The Role of Cognitive and Financial Constraints}

Other factors that could affect how spending responds to inflation expectations include financial constraints on households (e.g., McKay, Nakamura and Steinsson 2016) and cognitive constraints (Fahri and Werning 2018). To assess what role they play in driving our results, we verify to what extent households with different levels of financial or cognitive constraints respond to information treatments in the same way or whether these constraints lead to differential responses of expectations and actions.

We start by considering whether inflation expectations respond similarly to information treatments depending on individual characteristics. To maximize statistical power, we focus on the pooled treatment. ${ }^{12}$ The econometric specification is given by:

$$
\begin{aligned}
E_{i}^{\text {post }} \pi_{t+1}= & b_{0}+b_{1} \times E_{i}^{\text {prior }} \pi_{t+1}+b_{2} \times E_{i}^{\text {prior }} \pi_{t+1} \times \text { Treat }_{i}+b_{3} \times \text { Treat }_{i} \\
& +b_{4} \times E_{i}^{\text {prior }} \pi_{t+1} \times W_{i}+b_{5} \times E_{i}^{\text {prior }} \pi_{t+1} \times \text { Treat }_{i} \times W_{i} \\
& +b_{6} \times \text { Treat }_{i} \times W_{i}+b_{7} \times W_{i}+\text { error }_{i}
\end{aligned}
$$

where $W_{i}$ is some characteristic (level of thinking, education, income, etc.) of respondent $i$. To measure cognitive constraints, we classify respondents based on their level-k of thinking. We also consider splits of respondents based on their education and their income. ${ }^{13}$ To identify financial constraints, we rely on whether respondents have enough liquid savings to cover three months of non-durable good spending and, as a separate measure, on whether their financial wealth is greater than $€ 17,000$ (the median financial wealth of households participating in the survey). We report results in Table 7.

\footnotetext{
${ }^{12}$ Results differentiating by treatment type are available in Appendix Table 2.

${ }^{13}$ We also examined other sample splits (e.g., based on financial literacy). Results are broadly similar and available upon request.
} 
We find little evidence that the level of thinking has a discernable influence on how treatment affects inflation expectations. ${ }^{14}$ In a similar spirit, liquidity positions of respondents do not alter reactions to the treatment much. However, financial wealth has more of an effect on how beliefs respond to treatments: higher wealth agents place more weight on their priors and therefore respond less than agents with lower weight, on average. We also observe some differences by education and income: more educated individuals rely less on their priors when treated than less educated individuals, while the reverse is true for higher income respondents.

These differences in treatment effects on expectations, while not very large in an economic sense, still imply that there is a non-trivial amount of heterogeneity in the first stage of our regressions. For this reason, to assess the sensitivity of actions to these characteristics, we run separate IV regressions (2) for each subgroup of the population that we are interested in. We report results for how different forms of consumption respond to inflation expectations for different subgroups in Table 8.

Some of the results are striking. For example, we find some role for level- $k$ thinking in spending decisions (columns (1) and (2) of Table 8). With respect to spending on non-durables, $k=0$ individuals increase their spending while $k>0$ individuals tend to reduce their spending when their inflation expectations are higher. Higher level thinkers also reduce their consumption of durable goods more than lower-level thinkers, leading to a substantial difference in terms of how total spending responds to higher inflation expectations across the two groups. But notably, higher-level thinkers are the ones who significantly reduce their spending when inflation expectations are higher, which is the opposite of what one would expect from a simple consumption Euler equation logic. It is also the opposite of the effect required by Fahri and Werning (2018) to explain the forward guidance puzzle, since their proposal is that higher level thinkers will see their consumption rise more, not less, than lower-level thinkers when their inflation expectations increase.

Financial constraints also seem to be related to spending responses. As displayed in Table 8, we find that respondents who are more liquid (column (8)) or who have more financial wealth (column (10)) tend to reduce their durable spending relatively more compared to those who are less

\footnotetext{
${ }^{14}$ How the level of thinking influences treatment effects may depend on whether information in a treatment is public or private. We find that splitting the treatments does not yield statistical significance either (see column (1) of Appendix Table 2).
} 
liquid (column (7)) or have lower wealth (column (9)) when their inflation expectations rise. While the small change in spending following changes in inflation expectations for liquidity-constrained individuals is to be expected, the fact that spending on durable goods falls so sharply for the unconstrained is at odds with the logic in McKay, Nakamura and Steinsson (2016). In contrast, we find little difference based on education or income, which suggests that the differences identified based on cognitive and financial constraints are indeed capturing those forces.

We also provide evidence that cognitive and financial constraints have effects above and beyond those operating through expectations of future income or aggregate conditions. In Table 9, we consider how inflation expectations vary across different subgroups of the population. We find few significant differences in terms of how their expectations of future income or aggregate conditions vary. For different levels of thinking, for example, we find similar sensitivity of noninflation expectations to inflation expectations for $k=0$ and $k>0$ thinkers. Similarly, for different measures of financial constraints there are few differences in how non-inflation expectations respond to changes in inflation expectations. This suggests that it is the financial and cognitive constraints themselves which drive the differences in consumption behavior across sub-groups, not how these different groups interpret news about inflation, even though these constraints cannot themselves explain the observed average responses of different types of spending.

\section{Conclusion}

We provide new causal evidence on the effect of inflation expectations on households' decisions. Using a novel randomized control trial (RCT) design to identify exogenous variation in expectations and actions of households, we find that our information treatments generate significant, albeit small, effects on expectations. These effects on expectations then translate into households' spending decisions at least in the short-term. The implied effects are pronounced for durable goods spending but less clearly so for non-durable spending. We view the strong negative response of durable spending as reflecting the fact that households interpret higher inflation as temporarily reducing their future real income, which leads to little adjustment of non-durable spending but sharp delays and reductions in durable goods purchases to offset this transitory shock.

This result builds on a growing literature employing RCT methods to study microeconomic decisions underlying macroeconomic mechanisms. This approach provides a unique ability to generate exogenous variation in the beliefs of actual agents, in a setting where the effects of those 
changing beliefs on actions can be measured frequently in consecutive months. This specific application, how inflation expectations affect household decisions, is a central one in macroeconomic models but it is just one of many settings where this approach can be applied. We hope that this application serves as a stepping stone for more extensive use of randomized information treatments to characterize how expectations feed into the decisions of households and other agents.

The main result documented here, namely that exogenously higher inflation expectations lead to lower, rather than higher, spending on the part of households during the ELB has immediate policy implications. One is that policies that aim to affect expectations can work, in that exogenous changes in expectations clearly affect the decisions of households. But an immediate second implication is that doing so is rife with challenges. The way in which households interpret the information may be more complex than in the usual thought experiment. Changing inflation expectations, for example, can induce agents to also change their other economic expectations and, importantly, revise their consumption plans so that the ultimate effects on actions may differ from those intended. This suggests that communication of policies aimed to move inflation expectations should be more nuanced. Clearly, more research is needed to understand how agents make inferences about own financial situation as well as the underlying state of the economy and how the economy functions.

\section{References}

Afrouzi, Hassan, and Choongryul Yang. 2019. "Dynamic Inattention, the Phillips Curve, and Forward Guidance," Manuscript.

Andrade, Philippe, and Hervé Le Bihan. 2013. "Inattentive professional forecasters," Journal of Monetary Economics 60(8): 967-982.

Angeletos, George-Marios, and Chen Lian. 2018. "Forward Guidance without Common Knowledge," American Economic Review 108 (9): 2477-2512.

Armona, Luis, Andreas Fuster, and Basit Zafar. forthcoming. "Home Price Expectations and Behaviour: Evidence from a Randomized Information Experiment," Review of Economic Studies.

Bachmann, Rudiger, Tim O. Berg, and Eric R. Sims. 2015. "Inflation Expectations and Readiness to Spend: Cross-Sectional Evidence,” American Economic Journal: Economic Policy 7(1): 1-35. 
Belsley, A. David, Edwin Kuh, and Roy E. Welsch. 1980. Regression Diagnostics: Identifying Influential Data and Sources of Collinearity. New York: Wiley.

Bollen, A. Kenneth, and Robert W. Jackman. 1990. Regression diagnostics: An expository treatment of outliers and influential cases. In Modern Methods of Data Analysis, ed. J. Fox and J. S. Long, 257-291. Newbury Park, CA: Sage.

Camerer, Colin F. 1997. "Progress in Behavioral Game Theory," Journal of Economic Perspectives 11(4): 167-188.

Camerer, Colin F., Teck-Hua Ho, and Juin-Kuan Chong. 2004. "A Cognitive Hierarchy Model of Games," Quarterly Journal of Economics 119(3): 861-898.

Cavallo, Alberto, Guillermo Cruces, and Ricardo Perez-Truglia. 2017. "Inflation Expectations, Learning, and Supermarket Prices: Evidence from Survey Experiments," American Economic Journal: Macroeconomics 9(3): 1-35.

Chetty, Raj, and Adam Szeidl. 2007. “Consumption Commitments and Risk Preferences,” Quarterly Journal of Economics 122(2): 831-877.

Christensen, Celine, Peter van Els, and Maarten van Rooij. 2006. "Dutch households' perceptions of economic growth and inflation," De Economist 154(2): 277-294.

Coibion, Olivier, and Yuriy Gorodnichenko. 2012. "What can survey forecasts tell us about informational rigidities?” Journal of Political Economy 120(1): 116-159.

Coibion, Olivier, and Yuriy Gorodnichenko. 2015. "Information Rigidity and the Expectations Formation Process: A Simple Framework and New Facts," American Economic Review 105(8): 2644-2678.

Coibion, Olivier, Yuriy Gorodnichenko, and Dmitri Koustas. 2017. "Consumption Inequality and the Frequency of Purchases," NBER Working Paper w23357.

Coibion, Olivier, Yuriy Gorodnichenko, and Michael Weber. 2019. "Monetary Policy Communications and their Effects on Household Inflation Expectations," NBER Working Paper 25482.

Coibion, Olivier, Yuriy Gorodnichenko, and Saten Kumar. 2018. "How Do Firms Form Their Expectations? New Survey Evidence," American Economic Review 108(9): 2671-2713.

Coibion, Olivier, Yuriy Gorodnichenko, and Tiziano Ropele. 2018. "Inflation Expectations and Firm Decisions: New Causal Evidence,” NBER Working Paper 25412. 
Coibion, Olivier, Yuriy Gorodnichenko, Saten Kumar, and Jane Ryngaert. 2018. "Do You Know That I Know That You Know...? Higher-Order Beliefs in Survey Data," NBER Working Paper 24987.

Crump, Richard K., Stefano Eusepi, Andrea Tambalotti, and Giorgio Topa. 2015. "Subjective intertemporal substitution,” Staff Reports 734, Federal Reserve Bank of New York.

D'Acunto, Francesco, Daniel Hoang, and Michael Weber. 2016. "Unconventional Fiscal Policy, Inflation Expectations, and Consumption Expenditure," CESifo Working Paper Series 5793.

Del Negro, Marco, Marc Giannoni and Christina Patterson. 2015. "The Forward Guidance Puzzle," Federal Reserve Bank of New York Staff Reports, No. 574.

Dräger, Lena, and Giang Nghiem. 2018. “Are Consumers' Spending Decisions in Line with the Euler Equation?" Gutenberg School of Management and Economics \& Research Unit "Interdisciplinary Public Policy, Discussion Paper Series, 1802.

Duca, Ioana, Geoff Kenny, and Andreas Reuter. 2018. "Inflation Expectations, Consumption and the Lower Bound: Empirical Evidence from a Large Euro Area Survey,” ECB Working Paper 2196.

Fahri, Emmanuel, and Ivan Werning. 2018. "Monetary Policy, Bounded Rationality, and Incomplete Markets," Mimeo.

García-Schmidt, Mariana, and Michael Woodford. 2019. "Are Low Interest Rates Deflationary? A Paradox of Perfect-Foresight Analysis," American Economic Review 109(1): 86-120.

Gelman, Michael, Yuriy Gorodnichenko, Shachar Kariv, Dmitri Koustas, Matthew D. Shapiro, Dan Silverman, and Steven Tadelis. 2016. "The Response of Consumer Spending to Changes in Gasoline Prices,” NBER Working Paper 22969.

Ichiue, Hibiki, and Shusaku Nishiguchi. 2013. "Inflation Expectations and Consumer Spending at the Zero Bound: Micro Evidence," Bank of Japan Working Paper Series 13-E-11.

Jonung, Lars. 1981. "Perceived and Expected Rates of Inflation in Sweden," American Economic Review 71(5): 961-968.

Kamdar, Rupal. 2019. "The Inattentive Consumer: Sentiment and Expectations," manuscript.

Kaplan, Greg and Giovanni L. Violante. 2014. "A Model of the Consumption Response to Fiscal Stimulus Payments," Econometrica 82(4): 1199-1239.

Lusardi, Annamaria, and Olivia Mitchell. 2011. "Financial Literacy and Retirement Planning in the United States," Journal of Pension Economics and Finance 10 (4): 509-525. 
McKay, Alisdair, Emi Nakamura, and Jón Steinsson. 2016. "The Power of Forward Guidance Revisited," American Economic Review 106(10): 3133-3158.

Nagel, Rosemarie. 1995. "Unraveling in Guessing Games: An Experimental Study," American Economic Review 85(5): 1313-1326.

Nagel, Rosemarie, and John Duffy. 1997. "On the Robustness of Behavior in Experimental BeautyContest," Economic Journal 107(445): 1684-1700.

Teppa, Federica, and Corrie Vis. 2012. "The CentERpanel and the DNB household survey: Methodological aspects," DNB Occasional Studies 10(4). De Nederlandsche Bank.

Vellekoop, Nathanael, and Mirko Wiederholt. 2017. "Inflation Expectations and Choices of Households," Mimeo. 
Table 1. Descriptive statistics for various socioeconomic characteristics.

\begin{tabular}{|c|c|c|c|c|}
\hline & $\begin{array}{l}\text { Mean } \\
(1) \\
\end{array}$ & $\begin{array}{c}\text { Median } \\
(2) \\
\end{array}$ & $\begin{array}{c}\text { St.Dev. } \\
\text { (3) }\end{array}$ & $\begin{array}{l}\text { IQR } \\
(4) \\
\end{array}$ \\
\hline Age & 49.29 & 49.00 & 17.45 & 30.00 \\
\hline Female & 0.49 & 0.00 & 0.50 & 1.00 \\
\hline Education: Post-secondary & 0.29 & 0.00 & 0.45 & 1.00 \\
\hline Education: Secondary & 0.41 & 0.00 & 0.49 & 1.00 \\
\hline Education: Less than secondary & 0.30 & 0.00 & 0.46 & 1.00 \\
\hline Number of family members in the household & 2.21 & 2.00 & 1.14 & 2.00 \\
\hline Number of children & 0.50 & 0.00 & 0.90 & 1.00 \\
\hline Financial literacy score & 2.01 & 2.00 & 1.10 & 2.00 \\
\hline Net financial wealth, '000€ & 38.38 & 12.24 & 117.59 & 36.44 \\
\hline Household net income, $€$ & $2,647.40$ & $2,500.00$ & $1,571.36$ & $1,820.00$ \\
\hline Average monthly spending on non-durable goods over previous three months, $€$ & 627.57 & 480.00 & 678.65 & 600.00 \\
\hline Spending on durable goods over previous three months, $€$ & $1,166.45$ & 0.00 & $4,134.95$ & 500.00 \\
\hline \multicolumn{5}{|l|}{ Money in checking/saving accounts before receiving the last paycheck: } \\
\hline ' $000 €$ & 13.77 & 2.00 & 34.19 & 11.80 \\
\hline multiple of net monthly income & 6.61 & 0.88 & 51.54 & 4.90 \\
\hline multiple of monthly spending on non-durable goods & 45.80 & 5.00 & 225.29 & 26.17 \\
\hline
\end{tabular}

Notes: The table reports descriptive statistics for various household characteristics of survey participants. None of the variables is winsorized, censored, etc. "Money in checking/saving accounts before receiving the last paycheck" is based on the following question: "How much money did you have in your checking and savings accounts and in cash on the day before your last regular paycheck arrived? Please do not include fixed term deposits, stocks, bonds, mutual funds, or retirement accounts, etc." The multiple of net monthly income is the ratio of "money in checking/saving accounts..." to net monthly income reported in another survey question. The multiple of monthly spending on non-durable goods is the ratio of "money in checking/saving accounts..." to the average monthly spending on non-durables goods over the previous three months. IQR stands for interquartile range. 


\begin{tabular}{|c|c|c|c|c|c|c|}
\hline \multirow[b]{3}{*}{ Expectations (12-month ahead) for: } & \multicolumn{3}{|c|}{ Implied mean } & \multicolumn{3}{|c|}{$\begin{array}{c}\text { Implied uncertainty (standard } \\
\text { deviation) }\end{array}$} \\
\hline & Average & St.Dev. & $\begin{array}{c}\text { Corr. } \\
\text { with } \\
\text { inflation }\end{array}$ & Average & St.Dev. & $\begin{array}{c}\text { Corr. } \\
\text { with } \\
\text { inflation }\end{array}$ \\
\hline & $(1)$ & $(2)$ & $(3)$ & (4) & $(5)$ & $(6)$ \\
\hline Inflation & 1.98 & 2.14 & & 1.55 & 1.49 & \\
\hline \multicolumn{7}{|l|}{ Growth rates } \\
\hline Household spending on non-durable goods & 1.33 & 2.51 & 0.25 & 1.95 & 1.45 & 0.57 \\
\hline Economy-level spending on non-durable goods & 1.65 & 2.20 & 0.37 & 1.86 & 1.37 & 0.65 \\
\hline $\begin{array}{l}\text { Higher-order expectations: Economy-level spending on non-durable } \\
\text { goods }\end{array}$ & 1.79 & 1.95 & 0.42 & 2.03 & 1.42 & 0.64 \\
\hline Household net income & 0.95 & 2.95 & 0.12 & 1.18 & 1.20 & 0.66 \\
\hline
\end{tabular}

Notes: The table reports moments of various expectations elicited before survey participants are treated. All moments are based on the probability distributions reported by survey participants. Means (columns (1)-(3)) are computed as means implied by the generalized beta distribution fitted to each respondent separately. Uncertainty (columns (4)-(6)) is computed as standard deviation implied by the generalized beta distribution fitted to each respondent separately. Column (1) reports cross-section averages for implied means. Column (2) reports cross-sectional standard deviation for implied means. Column (3) reports the correlation between implied mean inflation expectations and implied mean expectation for another variable. Column (4) reports cross-section averages for implied uncertainty (standard deviation). Column (5) reports cross-sectional standard deviation for implied uncertainty (standard deviation). Column (6) reports the correlation between implied uncertainty (standard deviation) for inflation expectations and implied uncertainty (standard deviation) for expectation for another variable. Inflation expectations for various demographics groups are reported in Appendix Table 1. 
Table 3. Beliefs about distribution of other households' guesses.

\begin{tabular}{|c|c|c|c|c|c|c|c|c|}
\hline & \multicolumn{6}{|c|}{ Level of thinking } & \multirow{2}{*}{$\begin{array}{c}\text { Average } \\
\text { expected } \\
\text { distribution }\end{array}$} & \multirow{2}{*}{$\begin{array}{c}\text { Actual } \\
\text { distribution }\end{array}$} \\
\hline & $k=0$ & $k=0^{+}$ & $k=1$ & $k=2$ & $k=3$ & $k \geq 4$ & & \\
\hline & $(1)$ & (2) & (3) & (4) & $(5)$ & (6) & (7) & $(8)$ \\
\hline Share of respondents & 42.3 & 15.2 & 16.1 & 15.1 & 7.5 & 3.9 & & \\
\hline \multicolumn{9}{|c|}{ Panel A. Perceived distributions of others' guesses } \\
\hline \multicolumn{9}{|c|}{ Range of Guesses } \\
\hline From 0 to 9.99 & 5.7 & 5.6 & 5.5 & 6.3 & 11.6 & 22.2 & 6.7 & 3.7 \\
\hline From 10 to 19.99 & 6.7 & 7.3 & 7.5 & 10.4 & 16.9 & 10.1 & 8.3 & 7.0 \\
\hline From 20 to 29.99 & 8.5 & 9.8 & 11.8 & 19.0 & 12.3 & 9.3 & 11.0 & 13.4 \\
\hline From 30 to 39.99 & 10.3 & 12.5 & 21.8 & 17.3 & 12.6 & 11.4 & 13.7 & 16.8 \\
\hline From 40 to 49.99 & 12.1 & 18.4 & 14.1 & 11.9 & 10.1 & 8.6 & 13.1 & 11.8 \\
\hline From 50 to 59.99 & 15.3 & 17.3 & 12.6 & 11.6 & 10.5 & 10.3 & 14.1 & 11.3 \\
\hline From 60 to 69.99 & 14.9 & 10.7 & 9.4 & 7.7 & 8.0 & 7.2 & 11.6 & 15.9 \\
\hline From 70 to 79.99 & 11.9 & 7.5 & 7.1 & 6.0 & 6.6 & 8.3 & 9.2 & 14.0 \\
\hline From 80 to 89.99 & 8.0 & 5.7 & 5.4 & 5.0 & 5.7 & 6.3 & 6.6 & 4.5 \\
\hline From 90 to 100 & 6.6 & 5.3 & 4.8 & 4.7 & 5.9 & 6.3 & 5.8 & 1.4 \\
\hline
\end{tabular}

\section{Panel B. Consistency of responses}

Dependent variable: Guess $_{i}^{\text {Own }}$

$\begin{array}{lcccccc}E_{i}\left[\text { Guess }^{\mathrm{HO}}\right] & 1.30^{* * *} & 0.93^{* * *} & 0.73^{* * *} & 0.55^{* * *} & 0.31^{* * *} & 0.13^{* * *} \\ & (0.01) & (0.01) & (0.01) & (0.01) & (0.01) & (0.01) \\ & & & & & & \\ \text { Observations } & 739 & 254 & 282 & 226 & 118 & 61 \\ \mathrm{R}^{2} & 0.96 & 0.97 & 0.97 & 0.95 & 0.87 & 0.79 \\ \text { p-value(slope=2/3) } & 0.00 & 0.00 & 0.00 & 0.00 & 0.00 & 0.00\end{array}$

Notes: The table reports various moments for responses in the "beauty contest" game described in Section 3.3. Because there are many responses not equal to 33 , 22 , etc., we group responses in level of thinking as follows. $k=0$ includes everybody who reported a number greater than $50 . k=0^{+}$includes everybody who reported a number in $(40,50]$ range. $k=1$ includes everybody who reported a number in $(30,40]$ range. $k=2$ includes everybody who reported a number in $(20,30]$ range. $k=3$ includes everybody who reported a number in $(10,20]$ range. $k \geq 4$ includes everybody who reported a number in $(0,10]$ range. Panel B reports Huber-robust estimates of the slope in the following regression: Guess ${ }_{i}^{\text {Own }}=b \times E_{i}\left[\right.$ Guess $\left.^{\text {HO }}\right]+$ error $_{i}$ where Guess $S_{i}^{\text {Own }}$ is the guess submitted by person $i, E_{i}\left[\right.$ Guess $\left.^{\mathrm{HO}}\right]$ is person $i$ 's average guess for others' guesses. 
Table 4. Posterior inflation expectations as a function of treatment and prior inflation expectations.

\begin{tabular}{|c|c|c|c|c|c|c|c|}
\hline & \multicolumn{4}{|c|}{ Point prediction } & \multicolumn{3}{|c|}{ Implied mean } \\
\hline & Wave 1 & Wave 2 & Wave 3 & Wave 4 & Wave 2 & Wave 3 & Wave 4 \\
\hline & $(1)$ & $(2)$ & $(3)$ & $(4)$ & $(5)$ & $(6)$ & $(7)$ \\
\hline \multicolumn{8}{|c|}{ Panel A. Separate treatments } \\
\hline \multirow{2}{*}{ Prior } & $0.538 * * *$ & $0.108 * * *$ & $0.257 * * *$ & $0.251 * * *$ & "0.355*** & $0.297 * * *$ & $0.369 * * *$ \\
\hline & $(0.030)$ & $(0.030)$ & $(0.029)$ & $(0.033)$ & $(0.041)$ & $(0.034)$ & $(0.038)$ \\
\hline \multirow[t]{2}{*}{ Prior×Treatment (public) } & $-0.156 * * *$ & $0.212 * * *$ & 0.039 & 0.004 & 0.036 & $0.120 * *$ & -0.000 \\
\hline & $(0.045)$ & $(0.047)$ & $(0.043)$ & $(0.048)$ & $(0.056)$ & $(0.050)$ & $(0.053)$ \\
\hline \multirow[t]{2}{*}{ Treatment (public) } & 0.022 & $-0.450 * * *$ & 0.030 & 0.015 & -0.023 & $-0.198 *$ & -0.080 \\
\hline & $(0.100)$ & $(0.113)$ & $(0.109)$ & $(0.118)$ & $(0.135)$ & $(0.119)$ & $(0.127)$ \\
\hline \multirow[t]{2}{*}{ Prior×Treatment (private) } & $-0.210 * * *$ & $0.136 * * *$ & 0.027 & -0.025 & 0.075 & $0.312 * * *$ & 0.015 \\
\hline & $(0.043)$ & $(0.039)$ & $(0.039)$ & $(0.041)$ & $(0.053)$ & $(0.048)$ & $(0.051)$ \\
\hline \multirow[t]{2}{*}{ Treatment (private) } & 0.148 & $-0.313 * * *$ & -0.132 & -0.042 & -0.179 & $-0.627 * * *$ & -0.150 \\
\hline & $(0.097)$ & $(0.100)$ & $(0.102)$ & $(0.104)$ & $(0.130)$ & $(0.115)$ & $(0.124)$ \\
\hline \multirow[t]{2}{*}{ Constant } & $1.279 * * *$ & $2.160 * * *$ & $1.771 * * *$ & $1.760 * * *$ & $1.541 * * *$ & $1.579 * * *$ & $1.455 * * *$ \\
\hline & $(0.071)$ & $(0.077)$ & $(0.076)$ & $(0.081)$ & $(0.099)$ & $(0.084)$ & $(0.093)$ \\
\hline Observations & 1,778 & 1,545 & 1,534 & 1,500 & 1,621 & 1,603 & 1,579 \\
\hline R-squared & 0.337 & 0.114 & 0.170 & 0.129 & 0.212 & 0.297 & 0.238 \\
\hline F-stat for treatment & 13.79 & 5.918 & 1.933 & 0.906 & 0.779 & 11.21 & 0.760 \\
\hline \multicolumn{8}{|c|}{ Panel B. Pooled treatment } \\
\hline \multirow[t]{2}{*}{ Prior } & $0.540 * * *$ & $0.110 * * *$ & $0.258 * * *$ & $0.250 * * *$ & $0.354 * * *$ & $0.298 * * *$ & $0.370 * * *$ \\
\hline & $(0.030)$ & $(0.029)$ & $(0.029)$ & $(0.033)$ & $(0.041)$ & $(0.034)$ & $(0.038)$ \\
\hline \multirow[t]{2}{*}{ Prior $\times$ Treatment } & $-0.187 * * *$ & $0.161 * * *$ & 0.032 & -0.016 & 0.057 & $0.189 * * *$ & 0.007 \\
\hline & $(0.037)$ & $(0.036)$ & $(0.036)$ & $(0.039)$ & $(0.049)$ & $(0.042)$ & $(0.046)$ \\
\hline \multirow[t]{2}{*}{ Treatment } & 0.094 & $-0.357 * * *$ & -0.057 & -0.010 & -0.106 & $-0.370 * * *$ & -0.116 \\
\hline & $(0.085)$ & $(0.091)$ & $(0.091)$ & $(0.096)$ & $(0.117)$ & $(0.102)$ & $(0.110)$ \\
\hline \multirow[t]{2}{*}{ Constant } & $1.272 * * *$ & $2.151 * * *$ & $1.765 * * *$ & $1.760 * * *$ & $1.544 * * *$ & $1.580 * * *$ & $1.454 * * *$ \\
\hline & $(0.070)$ & $(0.076)$ & $(0.075)$ & $(0.081)$ & $(0.099)$ & $(0.085)$ & $(0.093)$ \\
\hline Observations & 1,778 & 1,543 & 1,533 & 1,500 & 1,621 & 1,606 & 1,579 \\
\hline R-squared & 0.339 & 0.112 & 0.170 & 0.126 & 0.210 & 0.269 & 0.238 \\
\hline F-stat for treatment & 27.16 & 10.58 & 0.403 & 0.276 & 0.702 & 9.965 & 1.284 \\
\hline
\end{tabular}

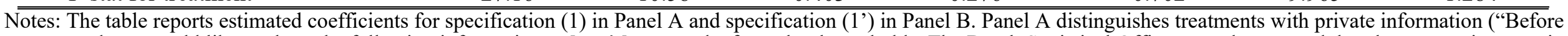

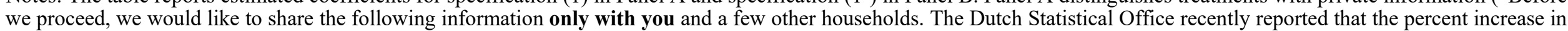

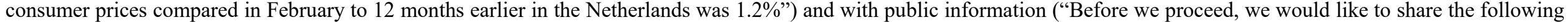

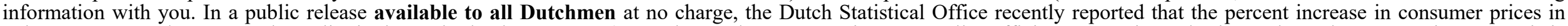

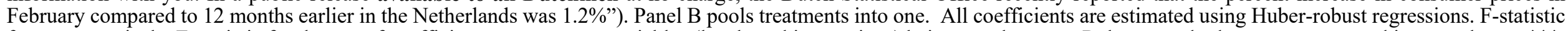

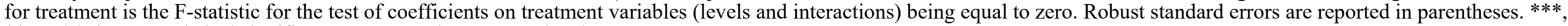
$* *$, and $*$ denote statistical significance at 1,5 and 10 percent levels. 
Table 5. Consumption response to changes in inflation expectations.

\begin{tabular}{|c|c|c|c|c|c|}
\hline \multirow{3}{*}{$\begin{array}{l}\text { Dep. var. is indicated in the title } \\
\text { of the panel }\end{array}$} & \multicolumn{4}{|c|}{ Actual spending, horizon, month } & \multirow{3}{*}{$\begin{array}{c}\text { Planned spending } \\
\text { Pooled } \\
(5)\end{array}$} \\
\hline & $\ln \left(C_{1}\right)$ & $\ln \left(C_{2}\right)$ & $\ln \left(C_{3}\right)$ & Pooled & \\
\hline & $(1)$ & $(2)$ & $(3)$ & (4) & \\
\hline \multicolumn{6}{|c|}{ Panel A. Spending on non-durable goods, $\log ($ spending $) * 100}$. \\
\hline Posterior inflation expectations & $\begin{array}{c}6.91 \\
(8.66)\end{array}$ & $\begin{array}{c}6.74 \\
(7.70)\end{array}$ & $\begin{array}{c}26.34 * \\
(13.60)\end{array}$ & $\begin{array}{c}9.12 * \\
(5.28)\end{array}$ & $\begin{array}{l}-0.15 \\
(5.83)\end{array}$ \\
\hline Observations & 945 & 924 & 888 & 2,735 & 1,627 \\
\hline R-squared & 0.34 & 0.40 & 0.25 & 0.35 & 0.36 \\
\hline $1^{\text {st }}$ stage F-stat & 15.69 & 14.61 & 12.10 & 40.27 & 27.19 \\
\hline
\end{tabular}

Panel B. Spending on durable goods, extensive margin, linear probability model.

Posterior inflation expectations

$-0.17^{*}$

$-0.29 * *$

$-0.33 * * *$

$-0.26 * * *$

$-0.13^{*}$

$(0.10)$

$(0.11)$

$(0.11)$

(0.06)

$(0.07)$

\begin{tabular}{lccccc}
\hline Observations & 1,088 & 999 & 940 & 3,014 & 1,636 \\
R-squared & 0.00 & -0.23 & -0.34 & -0.18 & 0.11 \\
$1^{\text {st }}$ stage F-stat & 10.78 & 8.325 & 11.19 & 29.09 & 8.70 \\
\hline \hline
\end{tabular}

Panel C. Spending on durable goods, intensive margin, log(spending)*100.

Posterior inflation expectations $\quad-60.31^{*}$

$(35.81)$

\begin{tabular}{lc}
\hline Observations & 329 \\
R-squared & 0.19 \\
$1^{\text {st }}$ stage F-stat & 12.05 \\
\hline \hline
\end{tabular}

Panel D. Spending on durable goods, IV Tobit, log(spending)*100.

$\begin{array}{llcccc}\text { Posterior inflation expectations } & -390.40 * & -552.89 * * & -825.64 * * * & -593.43 * * * & -658.36 * * \\ & (204.25) & (229.24) & (223.23) & (129.91) & (251.32)\end{array}$

\begin{tabular}{lccccc}
\hline Observations & 945 & 924 & 888 & 2,735 & 1,634 \\
$1^{\text {st }}$ stage F-stat & 15.69 & 14.61 & 12.10 & 40.27 & 18.25 \\
\hline \hline
\end{tabular}

Panel E. Total spending, $\log ($ spending $) * 100$.

Posterior inflation expectations

$-13.41$

$-7.14$

$-19.78$

$-13.95^{*}$

4.07

(11.34)

(11.50)

(18.34)

(7.59)

(9.83)

\begin{tabular}{|c|c|c|c|c|c|}
\hline Observations & 809 & 762 & 702 & 2,262 & 1,166 \\
\hline R-squared & 0.30 & 0.33 & 0.26 & 0.29 & 0.33 \\
\hline $1^{\text {st }}$ stage F-stat & 14.21 & 10.91 & 7.996 & 30.81 & 15.65 \\
\hline
\end{tabular}

Notes: The table reports estimated coefficient $\beta$ in specification (2) for various measures of consumer spending. Panel titles indicate which measure of consumer spending is used as an outcome variable. Columns (1)-(4) report estimates for actual spending. Column (5) reports results for spending planned in the second wave of the survey (specification (3')). All specifications are estimated using treatment and treatment interacted with prior inflation beliefs as instrumental variables (IV). Panel D reports coefficients in the IV Tobit regression. $1^{\text {st }}$ stage F-stat report the F-test for the coefficients on instrumental variables being equal to zero. Outliers and influential observations are identified and removed according to the procedure described in footnote 11. Robust standard errors are reported in parentheses. ***, **, and * denote statistical significance at 1, 5 and 10 percent levels. 
Response of other expectations immediately after the treatment

Household net income
Household spending on non-durable goods
Economy-level spending on nondurable goods Higher-order expectations: Economy-level spending on nondurable goods

\section{Panel A. Point predictions}

$\begin{array}{ccccc}E_{i t}^{\text {post }} \pi_{t+1} & 0.58 & -2.39^{* *} & -2.07^{*} & -3.19^{* *} \\ & (1.10) & (1.15) & (1.20) & (1.48)\end{array}$

\begin{tabular}{lcccc}
\hline Observations & 1,224 & 1,207 & 1,141 & 1,061 \\
R-squared & 0.20 & -0.04 & -0.07 & -0.10 \\
$1^{\text {st }}$ stage F-stat & 18.72 & 20.66 & 18.16 & 19.15 \\
\hline \hline
\end{tabular}

Household income expectations in subsequent waves

\begin{tabular}{cccc}
\hline Wave 2 & Wave 3 & Wave 4 & Pooled \\
\hline & & & \\
$1.10^{*}$ & -0.48 & -0.46 & 0.13 \\
$(0.60)$ & $(0.58)$ & $(0.61)$ & $(0.30)$
\end{tabular}

\begin{tabular}{lcccc}
\hline Observations & 972 & 969 & 964 & 2,891 \\
R-squared & 0.23 & 0.23 & 0.29 & 0.29 \\
$1^{\text {st }}$ stage F-stat & 9.17 & 9.17 & 8.12 & 27.85 \\
\hline
\end{tabular}

Panel C. Implied standard deviation (uncertainty)
$E_{i t}^{\text {post }} \pi_{t+1}$
$-0.62 * *$
$(0.25)$
$-0.01$
$-0.53 * *$
$-0.28 * * *$
$(0.15)$
$(0.24)$

\begin{tabular}{lcccc}
\hline Observations & 974 & 960 & 966 & 2,886 \\
R-squared & 0.00 & 0.36 & 0.03 & 0.25 \\
$1^{\text {st }}$ stage F-stat & 8.18 & 8.61 & 7.55 & 25.27 \\
\hline \hline
\end{tabular}

Notes: The table reports estimated coefficient $b_{1}$ in specification (3). Outcome variables on Panel A are measured in the first wave immediately after the treatment. All outcome variables are measured as point predictions. Panel B reports results for implied mean of expected growth rate of household income over the next 12 months. Panel C reports results for implied uncertainty (standard deviation) of expected growth rate of household income over the next 12 months. Outcome variables in Panels B and C are based on probability distributions reported by respondents. All specifications are estimated using treatment and treatment interacted with prior inflation beliefs as instrumental variables (IV). Treatments are pooled. $1^{\text {st }}$ stage F-stat report the F-test for the coefficients on instrumental variables being equal to zero. Outliers and influential observations are identified and removed according to the procedure described in footnote 11 . Robust standard errors are reported in parentheses. ${ }^{* * *}, * *$, and $*$ denote statistical significance at 1,5 and 10 percent levels. 


\begin{tabular}{|c|c|c|c|c|c|}
\hline & \multicolumn{5}{|c|}{ Respondents' characteristic $W$} \\
\hline & $\begin{array}{l}\text { Level of } \\
\text { thinking } k\end{array}$ & $\begin{array}{l}\text { College- } \\
\text { level } \\
\text { education }\end{array}$ & $\begin{array}{c}\text { Log gross } \\
\text { monthly } \\
\text { income }\end{array}$ & $\begin{array}{l}\text { Money in liquid } \\
\text { accounts enough to } \\
\text { cover } 3 \text { months on } \\
\text { non-durable } \\
\text { consumption }\end{array}$ & $\begin{array}{l}\text { Financial } \\
\text { wealth is } \\
\text { greater } \\
\text { than } \\
€ 17,000\end{array}$ \\
\hline & $(1)$ & $(2)$ & (3) & $(4)$ & $(5)$ \\
\hline \multirow[t]{2}{*}{ Prior } & $0.563 * * *$ & $0.459 * * *$ & $0.487 * * *$ & $0.604 * * *$ & $0.582 * * *$ \\
\hline & $(0.036)$ & $(0.037)$ & $(0.031)$ & $(0.047)$ & $(0.042)$ \\
\hline \multirow[t]{2}{*}{ Prior $\times$ Treatment } & $-0.139 * * *$ & $-0.104 * *$ & $-0.117 * * *$ & $-0.220 * * *$ & $-0.299 * * *$ \\
\hline & $(0.045)$ & $(0.045)$ & $(0.039)$ & $(0.062)$ & $(0.051)$ \\
\hline \multirow[t]{2}{*}{$W \times$ Treatment } & -0.001 & $0.310 *$ & $-0.367 * * *$ & 0.096 & $-0.467 * *$ \\
\hline & $(0.075)$ & $(0.181)$ & $(0.131)$ & $(0.185)$ & $(0.194)$ \\
\hline \multirow[t]{2}{*}{ Prior $\times W \times$ Treatment } & -0.015 & $-0.189 * *$ & $0.266 * * *$ & 0.062 & $0.329 * * *$ \\
\hline & $(0.034)$ & $(0.083)$ & $(0.057)$ & $(0.082)$ & $(0.084)$ \\
\hline \multirow{2}{*}{ Prior $\times W$} & $-0.061 * *$ & $0.174 * * *$ & $-0.216 * * *$ & -0.046 & $-0.195 * * *$ \\
\hline & $(0.028)$ & $(0.066)$ & $(0.053)$ & $(0.064)$ & $(0.069)$ \\
\hline \multirow[t]{2}{*}{ Treatment } & 0.019 & -0.057 & -0.050 & 0.044 & 0.199 \\
\hline & $(0.107)$ & $(0.108)$ & $(0.088)$ & $(0.141)$ & $(0.124)$ \\
\hline \multirow[t]{2}{*}{$W$} & 0.077 & $-0.371 * *$ & $0.269 * *$ & -0.029 & $0.384 * *$ \\
\hline & $(0.063)$ & $(0.149)$ & $(0.121)$ & $(0.149)$ & $(0.164)$ \\
\hline Observations & 1,694 & 1,780 & 1,657 & 1,323 & 1,478 \\
\hline R-squared & 0.352 & 0.324 & 0.366 & 0.392 & 0.328 \\
\hline
\end{tabular}

Notes: The table reports estimated coefficients in specification (4). Posterior inflation expectations are measured in the first wave immediately after the treatment. The title of each column indicates which variable is used as $W$ in specification (4). Log gross monthly income (column (3)) is normalized to have zero mean. Variables $W$ in columns (2), (4) and (5) are indicator variables. All specifications are estimated using treatment and treatment interacted with prior inflation beliefs as instrumental variables (IV). Treatments are pooled. Outliers and influential observations are identified and removed according to the procedure described in footnote 11. Robust standard errors are reported in parentheses. ${ }^{* *}, * *$, and $*$ denote statistical significance at 1,5 and 10 percent levels. 
Table 8. Heterogeneity in consumption response to changes in inflation expectations.

Dependent variable is indicated in the title of the panel

\begin{tabular}{|c|c|c|c|c|c|c|c|c|c|}
\hline \multicolumn{10}{|c|}{ Sample split by: } \\
\hline \multicolumn{2}{|c|}{ Level of thinking } & \multicolumn{2}{|c|}{$\begin{array}{l}\text { College-level } \\
\text { education }\end{array}$} & \multicolumn{2}{|c|}{$\begin{array}{l}\text { Gross monthly } \\
\text { income is greater than } \\
\text { the mean }\end{array}$} & \multicolumn{2}{|c|}{$\begin{array}{l}\text { Money in liquid } \\
\text { accounts enough to } \\
\text { cover } 3 \text { months on } \\
\text { non-durable } \\
\text { consumption } \\
\end{array}$} & \multicolumn{2}{|c|}{$\begin{array}{l}\text { Financial wealth is } \\
\text { greater than } € 17,000\end{array}$} \\
\hline$k=0$ & $k \geq 1$ & No & Yes & No & Yes & No & Yes & No & Yes \\
\hline (1) & (2) & (3) & (4) & (5) & (6) & (7) & (8) & (9) & $\begin{array}{l}(10) \\
\end{array}$ \\
\hline
\end{tabular}

Panel A. Spending on non-durable goods, $\log ($ spending)* 100 .

Posterior inflation expectations

$10.41^{*}$
$(5.76)$

$-11.25$

10.05

05

$1,6070.131,083$

1,562

$\begin{array}{r}6.23 \\ (10.04) \\ 0.75 \quad 1,173 \\ \hline\end{array}$

$\begin{array}{cc}-0.14 & 15.86 * * \\ (8.80) & (6.95)\end{array}$
$\begin{array}{ll}13.17 & 12.64 \\ (8.29) & (9.18)\end{array}$
9.18)

$\begin{array}{ll}995 & \\ & 0.97\end{array}$

$13.19 * *$ $\begin{array}{ll}(6.50) & -0.60 \\ (10.56)\end{array}$

Observations
p-value equality

$29.21 \quad 9.399$

$22.40 \quad 25.91$

$11.00 \quad 31.53$

1,048
0.27

$1^{\text {st }}$ stage F-stat

Panel B. Spending on durable goods, extensive margin, linear probability model.

Posterior inflation expectations

$-0.23 * *$
$(0.07)$

$-0.44 * * *$

$-0.29 * * * \quad-0.20 *$

$(0.07)$

$(0.11)$

$-0.29 * * * \quad-0.22 * * *$

17.83

14.89

$1,793 \quad 0.51$

1,221

(0.09)

$\frac{(0.08)}{1,765}^{1.78^{16.89}}$

$\begin{array}{r}-0.19 \\ (0.09) \\ \hline 986\end{array}$

\begin{tabular}{ll}
$17.71 \quad 16.17$ \\
\hline
\end{tabular}

$17.47 \quad 8.151$

$8.151 \quad 17.711^{0.51} 16.17$

$\begin{array}{lrr} & 0.58 & \\ 8.31 & 26.89\end{array}$

986

$10.90 \quad 20.01$

$-0.30 * * *$
$(0.09)$
1,544
20.01

\begin{tabular}{lc}
$-0.16 * * *$ & $-0.28 * *$ \\
$(0.06)$ & $(0.13)$ \\
\hline 1,210 & \multicolumn{1}{c}{1,424} \\
20.16 & 0.36 \\
\hline
\end{tabular}

\section{Panel C. Spending on durable goods, IV Tobit, $\log ($ spending)*100
Posterior inflation expectations $(\times 100) \quad-5.66 * * *-10.03 * *$}

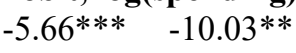

Observations
p-value equality

p-value equality
$1^{\text {st }}$ stage F-stat

$12.79 \quad 6.588$

$13.733^{0.37} 13.85$

$\begin{array}{ll}1,160 & \\ & 0.36\end{array}$

$.36 \begin{aligned} & 1,848 \\ & 21.49\end{aligned}$

7.576

0.51

, 537

1,208

0.70

\section{Panel D. Total spending, $\log ($ spending $) * 100$}

Posterior inflation expectations -2.12

Observations

p-value equality

$1^{\text {st }}$ stage F-stat

\begin{tabular}{cccc}
-2.12 & $-30.74 * *$ & -12.91 & -18.63 \\
$(10.00)$ & $(13.22)$ & $(8.44)$ & $(17.75)$ \\
\hline 1,308 & 919 & 1,263 & 999 \\
& 0.08 & \multicolumn{2}{c}{0.77}
\end{tabular}

6.97

21.49

\begin{tabular}{cc}
$-22.07 * *$ & $-7.08 *$ \\
$(11.14)$ & $(10.55)$ \\
\hline 874 & 1,388
\end{tabular}

\begin{tabular}{cccc}
10.41 & $-25.31 * *$ & -1.89 & $-39.49^{* *}$ \\
$(12.98)$ & $(12.26)$ & $(7.98)$ & $(17.55)$ \\
835 & 1,297 & 896 & 1,108 \\
& & \multicolumn{2}{c}{0.05} \\
11.40 & 15.81 & 20.30 & 11.84
\end{tabular}

17.06

14.23

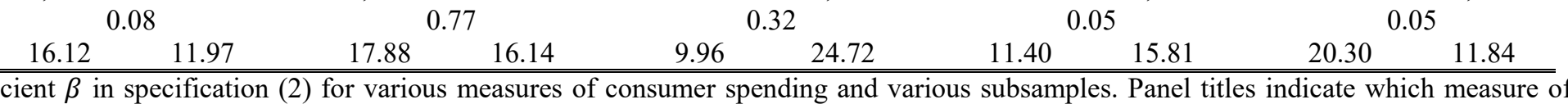

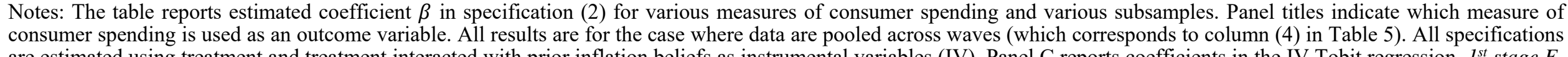

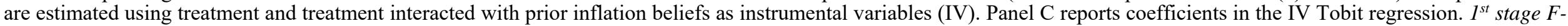

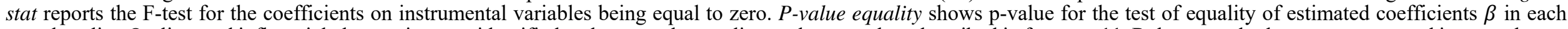

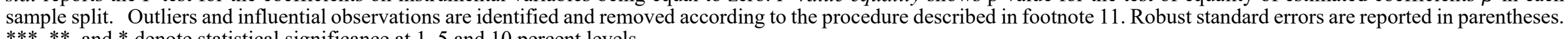
$* * *, * *$, and $*$ denote statistical significance at 1,5 and 10 percent levels. 
Sample split

Level of thinking $\quad k=0 \quad E_{i t}^{\text {post }} \pi_{t+1}$

\begin{tabular}{ccc} 
& & \\
& Observations & \\
& $1^{\text {st }}$ stage F-stat & 8.13 \\
\hline$k>0$ & $E_{i t}^{\text {post }} \pi_{t+1}$ & -0.0 \\
& Observations & $(1.7$
\end{tabular}

College-leve education

Observations
$1^{\text {st }}$ stage F-stat

\section{education}

No

\begin{tabular}{ll} 
& $E_{i t} \pi_{t+1}$ \\
\cline { 2 - 3 } & Observations \\
$1^{\text {st }}$ stage F-stat
\end{tabular}

\begin{tabular}{ll}
\hline Yes & \\
& \\
\cline { 2 - 2 } & $1^{\text {st }}$ \\
& $1^{\text {st }}$ st \\
p-value equal \\
No
\end{tabular}

Gross monthly No income is greater than the mean

$E_{i t}^{p o s t} \pi_{t+1}$

Dependent variable: post-treatment expectations (point predictions)

$\begin{array}{ccc}\begin{array}{c}\text { Household net } \\ \text { income }\end{array} & \begin{array}{c}\text { Household } \\ \text { spending on } \\ \text { non-durable } \\ \text { goods }\end{array} & \begin{array}{c}\text { Economy-level } \\ \text { spending on } \\ \text { non-durable } \\ \text { goods }\end{array}\end{array}$
Higher-order
expectations:
Economy-level
spending on non-
durable goods

(2)

$\begin{array}{cc}(1) & (2) \\ -0.28 & -2.56\end{array}$

$-0.28$

$-2.56^{*}$

694

$(1.39)$

8.132

676

$-0.09$

11.71

(3)

$-3.80^{*}$

(2.05)

652

8.852

$-1.61$

$-3.12$

$(1.71)$

(2.54)

$462 \quad 462$

462
6.476
0.846

(2.48)

8.834

0.846

0.937

$-0.28$

(1.23)

682

10.44

0.91

(2.45)

$-3.62 * *$

(1.66)

665

10.07

424

4.652

0.496

(4)

$-3.08$

(1.93)

602

10.14

$-3.07$

(3.30)

402

5.783

$-5.68 * *$

0.996

(2.54)

628

6.485

$-5.03 * *$

(2.54)

$-1.66$

(1.95)

493

492

9.259

11.85

0.664

0.442

0.53

(1.63)

477

$-3.74 *$

(2.04)

471

6.457

$1^{\text {st }}$ stage F-stat

$-0.32$

7.036

1.33

8.341

Yes $E_{i t}^{\text {post }} \pi_{t+1}$

(1.60)

Observations

698

11.12

p-value equal.

Money in liquid

to cover 3

months on non-

durable

consumption

No

$$
\text { ual. }
$$

0.764

$-2.07$

(1.96)

$-2.31$

(1.81)

$-0.85$

(1.71)

465

13.09

432

13.09

15.05

$-4.31$

(2.63)

439

0.172

(1)

(1.64)

686

12.23

405

Observations

8.616

0.301

2.44

(1.81)

Yes $\quad E_{i t}^{\text {post }} \pi_{t+1}$

643

Observations

6.609

$-4.98^{*}$

(2.57)

0.091

409

5.113

$-3.39$

(2.54)

$1^{\text {st }}$ stage F-stat

p-value equal.

Financial wealth No

is greater than

$€ 17,000$

\begin{tabular}{lc}
\multicolumn{1}{c}{$E_{i t}^{\text {post }} \pi_{t+1}$} & -1.82 \\
& $(1.20)$ \\
\hline Observations & 449 \\
$1^{\text {st }}$ stage F-stat & 15.75 \\
$E_{i t}^{\text {post }} \pi_{t+1}$ & 4.81 \\
& $(3.65)$ \\
\hline Observations & 574 \\
$1^{\text {st }}$ stage F-stat & 2.774 \\
\hline
\end{tabular}

$-1.82$

449

8.784

$-1.40$

(1.51)

629

9.107

$-1.54$

6.933

(1.75)

$-2.65$

654

(2.24)

9.388

617

0.735

11.66

$-7.63^{* *}$

0.609

$(3.33)$

$-5.98$

(3.73)

385

349

6.393

6.040

$-1.33$

(1.95)

$-2.81$

(1.94)

606

569

6.235

9.273

0.230

0.102

0.451

$-2.18^{*}$

(1.30)

$\begin{array}{ll}5.75 & 446\end{array}$

446
19.02

$-3.31$

(3.20)

551

$-3.25 * *$

(1.61)

$-3.81^{* *}$

(1.83)

Yes

p-value equal.

0.085

3.485

0.744

410

384

17.03

12.82

$-2.88$

(3.96)

(3.62)

508

540

3.450

0.745

0.830

Notes: The table reports estimated coefficient $b_{1}$ in specification (3). All outcome variables are measured in the first wave immediately after the treatment. The two left columns indicate which sample is used for estimation. All specifications are estimated using treatment and treatment interacted with prior inflation beliefs as instrumental variables (IV). Treatments are pooled. ${ }^{\text {st }}$ stage F-stat report the F-test for the coefficients on instrumental variables being equal to zero. Outliers and influential observations are identified and removed according to the procedure described in footnote 11. Robust standard errors are reported in parentheses. $* * *, * *$, and $*$ denote statistical significance at 1,5 and 10 percent levels. $P$-value equality shows $\mathrm{p}$-value for the test of equality of estimated coefficients $\beta$ in each sample split. 
Figure 1. Level-k responses.

Panel A: All responses

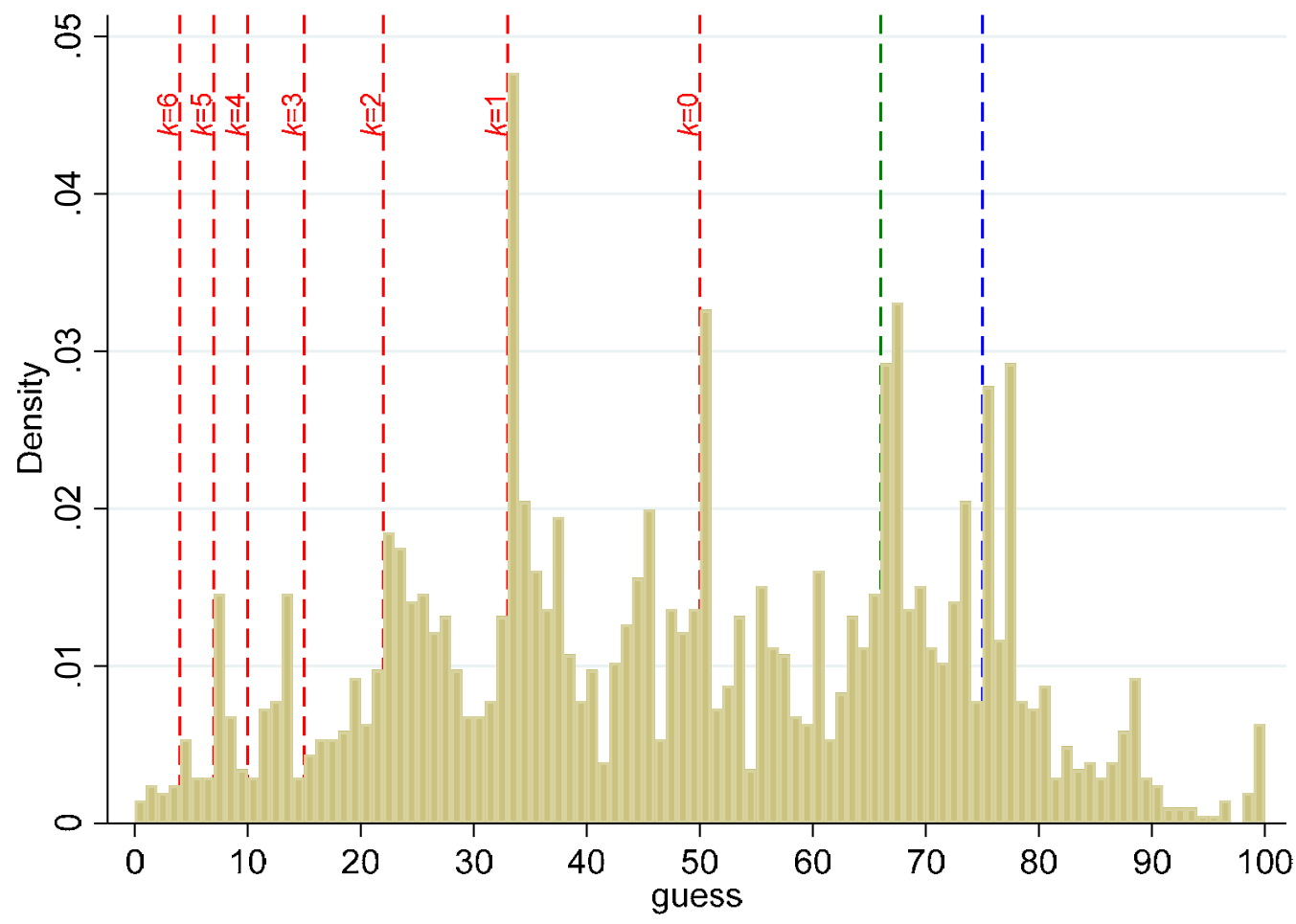

Panel B. Responses by age

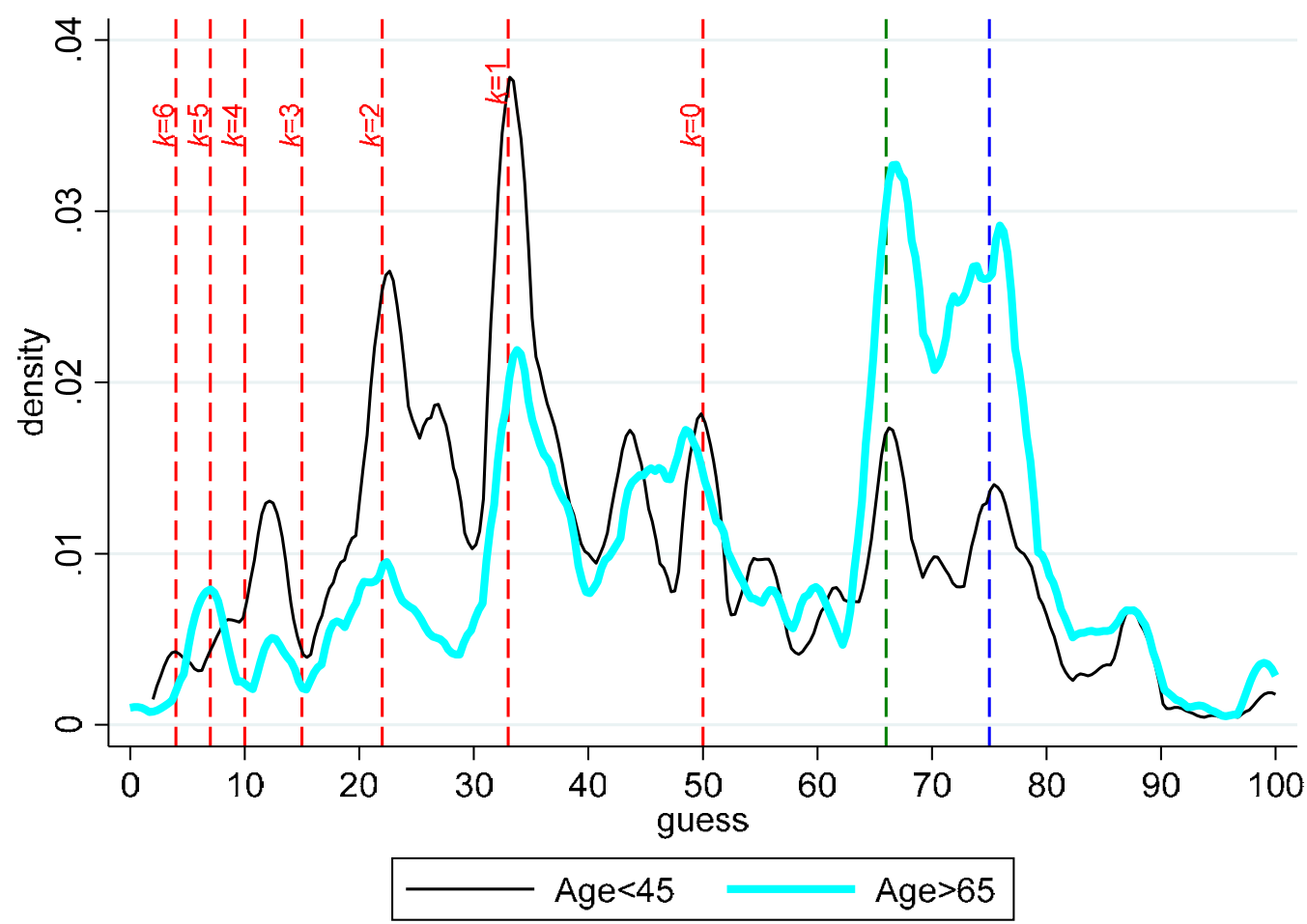

Notes: The figure reports the distribution of responses in the "beauty contest" game described in Section 3.3. Red vertical lines indicate values of $k$, blue lines indicate responses one would observe if individuals pick $(3 / 2)^{k} \times 50$ (that is, people use $(3 / 2)$ rather than $(2 / 3)$ ), and the green line indicates $(2 / 3) \times 100$. Panel A reports the histogram for the full sample. Panel B reports kernel densities for sample splits based on respondents' age. 

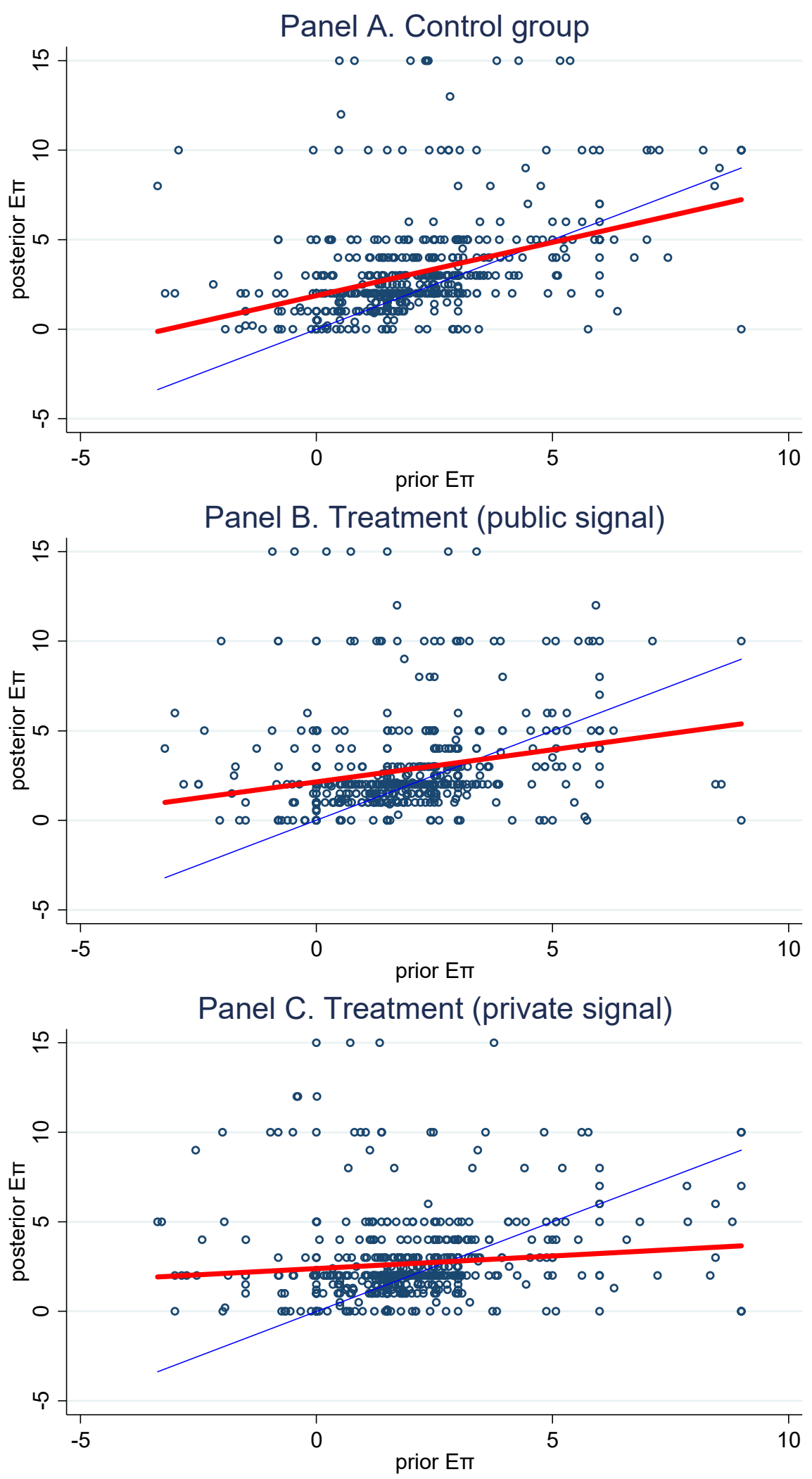

Notes: Each panel presents a scatterplot of post-treatment inflation expectations (point prediction immediately after treatment) and pre-treatment inflation expectations (implied mean from the reported distribution) by treatment group. The thin blue line is the 45degree line. The thick red line is the fitted line. 


\section{APPENDiX A}

\section{AdDitional Figures AND TABLES}




\begin{tabular}{|c|c|c|c|c|}
\hline & \multicolumn{2}{|c|}{ Implied mean } & \multicolumn{2}{|c|}{$\begin{array}{l}\text { Implied uncertainty } \\
\text { (standard deviation) }\end{array}$} \\
\hline & Average & St.Dev. & Average & St.Dev. \\
\hline & $(1)$ & $(2)$ & (3) & (4) \\
\hline \multicolumn{5}{|l|}{ Level of thinking } \\
\hline$k=0$ & 2.09 & 2.14 & 1.54 & 1.47 \\
\hline$k=1$ & 1.96 & 1.75 & 1.36 & 1.20 \\
\hline$k=2$ & 1.59 & 1.95 & 1.57 & 1.45 \\
\hline$k=3$ & 1.94 & 2.31 & 1.57 & 1.60 \\
\hline$k \geq 4$ & 2.19 & 2.33 & 1.95 & 1.86 \\
\hline \multicolumn{5}{|l|}{ Gender } \\
\hline Male & 2.13 & 1.91 & 1.35 & 1.29 \\
\hline Female & 1.89 & 2.34 & 1.66 & 1.59 \\
\hline \multicolumn{5}{|l|}{ Education } \\
\hline Less than secondary & 2.15 & 2.21 & 1.66 & 1.71 \\
\hline Secondary & 1.97 & 2.37 & 1.71 & 1.50 \\
\hline Post-secondary & 1.87 & 1.54 & 1.20 & 1.08 \\
\hline \multicolumn{5}{|l|}{ Liquidity constraint } \\
\hline Hand-to-mouth & 2.01 & 2.03 & 1.58 & 1.48 \\
\hline Not hand-to-mouth & 2.07 & 1.65 & 1.24 & 1.08 \\
\hline \multicolumn{5}{|l|}{ Financial literacy score } \\
\hline 0 & 1.23 & 3.42 & 2.92 & 2.09 \\
\hline 1 & 2.14 & 2.22 & 1.99 & 1.78 \\
\hline 2 & 2.02 & 2.31 & 1.62 & 1.43 \\
\hline 3 & 2.08 & 1.55 & 1.12 & 1.00 \\
\hline \multicolumn{5}{|c|}{ Gross monthly income above mean } \\
\hline No & 2.00 & 2.36 & 1.75 & 1.60 \\
\hline Yes & 1.97 & 1.96 & 1.42 & 1.39 \\
\hline \multicolumn{5}{|c|}{ Financial wealth above $€ 17,000$} \\
\hline No & 1.91 & 2.35 & 1.73 & 1.59 \\
\hline Yes & 2.11 & 1.82 & 1.20 & 1.16 \\
\hline
\end{tabular}

Notes: Hand-to-mouth is defined as a household that has liquid wealth smaller than three month of average monthly spending on non-durable goods. Inflation expectations are for one-year-ahead horizon. 


\begin{tabular}{|c|c|c|c|c|c|}
\hline & \multicolumn{5}{|c|}{ Respondents' characteristic $X$} \\
\hline & $\begin{array}{c}\text { Level of } \\
\text { thinking } k\end{array}$ & $\begin{array}{c}\text { College- } \\
\text { level } \\
\text { education }\end{array}$ & $\begin{array}{l}\text { Log gross } \\
\text { monthly } \\
\text { income }\end{array}$ & $\begin{array}{c}\text { Money in liquid } \\
\text { accounts enough to } \\
\text { cover } 3 \text { months on } \\
\text { non-durable } \\
\text { consumption }\end{array}$ & $\begin{array}{l}\text { Financial } \\
\text { wealth is } \\
\text { greater } \\
\text { than } \\
€ 17,000\end{array}$ \\
\hline & $(1)$ & $(2)$ & (3) & $(4)$ & $(5)$ \\
\hline \multirow[t]{2}{*}{ Prior } & $0.567 * * *$ & $0.458 * * *$ & $0.487 * * *$ & $0.599 * * *$ & $0.581 * * *$ \\
\hline & $(0.035)$ & $(0.037)$ & $(0.032)$ & $(0.048)$ & $(0.042)$ \\
\hline \multirow[t]{2}{*}{ Prior $\times$ Treatment $(\mathrm{Pub})$} & $-0.132 * *$ & -0.007 & $-0.089 * *$ & 0.001 & $-0.260 * * *$ \\
\hline & $(0.053)$ & $(0.053)$ & $(0.045)$ & $(0.068)$ & $(0.064)$ \\
\hline \multirow[t]{2}{*}{ Prior $\times$ Treatment $($ Pri) } & $-0.158 * * *$ & $-0.159 * * *$ & $-0.128 * * *$ & $-0.362 * * *$ & $-0.325 * * *$ \\
\hline & $(0.050)$ & $(0.050)$ & $(0.044)$ & $(0.065)$ & $(0.057)$ \\
\hline \multirow[t]{2}{*}{$W \times$ Treatment $(\mathrm{Pub})$} & -0.099 & $0.464 * *$ & -0.210 & $0.677 * * *$ & -0.330 \\
\hline & $(0.087)$ & $(0.207)$ & $(0.142)$ & $(0.200)$ & $(0.225)$ \\
\hline \multirow[t]{2}{*}{$W \times$ Treatment $($ Pri) } & 0.049 & 0.218 & $-0.353 * * *$ & $-0.429 * *$ & $-0.611 * * *$ \\
\hline & $(0.081)$ & $(0.208)$ & $(0.135)$ & $(0.218)$ & $(0.221)$ \\
\hline \multirow{2}{*}{ Prior $\times W \times$ Treatment $(\mathrm{Pub})$} & 0.022 & $-0.359 * * *$ & $0.150 * *$ & $-0.227 * *$ & $0.202 * *$ \\
\hline & $(0.040)$ & $(0.095)$ & $(0.062)$ & $(0.091)$ & $(0.100)$ \\
\hline \multirow{2}{*}{ Prior $\times W \times$ Treatment (Pri) } & -0.017 & -0.072 & $0.291 * * *$ & $0.283 * * *$ & $0.452 * * *$ \\
\hline & $(0.036)$ & $(0.095)$ & $(0.054)$ & $(0.096)$ & $(0.096)$ \\
\hline \multirow[t]{2}{*}{ Prior $\times W$} & $-0.058 * *$ & $0.176^{* * *}$ & $-0.218 * * *$ & -0.025 & $-0.194 * * *$ \\
\hline & $(0.027)$ & $(0.067)$ & $(0.053)$ & $(0.066)$ & $(0.070)$ \\
\hline \multirow[t]{2}{*}{ Treatment (Pub) } & 0.028 & -0.186 & -0.099 & $-0.385 * *$ & 0.147 \\
\hline & $(0.121)$ & $(0.126)$ & $(0.102)$ & $(0.150)$ & $(0.146)$ \\
\hline \multirow[t]{2}{*}{ Treatment (Pri) } & 0.035 & 0.006 & -0.022 & $0.379 * *$ & $0.235^{*}$ \\
\hline & $(0.120)$ & $(0.120)$ & $(0.100)$ & $(0.156)$ & $(0.140)$ \\
\hline \multirow[t]{2}{*}{$W$} & 0.073 & $-0.377 * *$ & $0.270 * *$ & -0.067 & $0.380 * *$ \\
\hline & $(0.063)$ & $(0.150)$ & $(0.122)$ & $(0.153)$ & $(0.166)$ \\
\hline Observations & 1,688 & 1,783 & 1,661 & 1,323 & 1,483 \\
\hline R-squared & 0.362 & 0.332 & 0.372 & 0.405 & 0.332 \\
\hline
\end{tabular}

Notes: see notes to Table 4 and Table 7. 


\section{APPENDIX B}

\section{QUESTIONNAIRES}




\section{PROGRAMMING INFORMATION}

\section{QUESTION BLOCK}

12. This question is being asked to all participants in this survey. These participants are representative of the Dutch population.

Please choose a number from zero to 100.

We will take your number as well as the numbers chosen by other participants to calculate the average number. The winning number will be the number that is closest to two-thirds (2/3) of the average number.

The participant who filled in the winning number will receive 500 euro (if more participants have filled in the winning number, the 500 euro will be divided equally among the winners).

Please take your time to answer this question.

Your chosen number is:

[ ] I do not want participate

13. Like you, other participants in this survey are asked to choose a number from zero to 100 , with the goal of making their choice as close as possible to two-thirds (2/3) of the average choice of all participants. What percentage of other participants do you think chooses a number that falls in the listed ranges in the table below?

\section{Chosen numbers}

From 0 to 9.99

From 10 to 19.99

From 20 to 29.99

From 30 to 39.99

From 40 to 49.99

From 50 to 59.99

From 60 to 69.99

From 70 to 79.99

From 80 to 89.99

From 90 to 100

Total (the percentages should sum to 100):

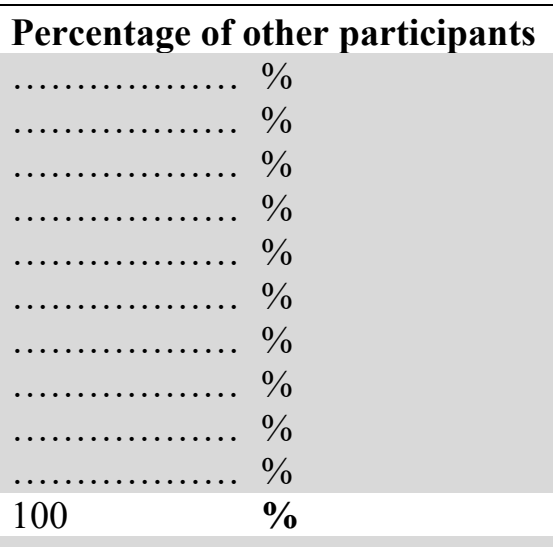

[ ] I do not know

1. How much did your household spend in total on purchases of durable goods in the last three months (January 2018 to March 2018)?

Durable goods are goods that last in time, including for instance cars, electronics, kitchen appliances, furniture, house maintenance, jewelries, etc. (please exclude purchases of houses, apartments, etc.). Please provide an answer in euros.

Answer:................ euros

... I did not buy any durables

... I do not know 
2. What do you think your household's spending on purchases of durable goods will be per month in the next three months (April, May and June)? Please provide an answer in euros.

April: ............. euros
$\ldots$ I do not have plans to buy durables in this month
$\ldots$ I do not know
May: ............ euros
$\ldots$ I do not have plans to buy durables in this month
$\ldots$ I do not know
June: $\ldots . \ldots \ldots \ldots \ldots . .$. euros
$\ldots$ I do not have plans to buy durables in this month
$\ldots$ I do not know

3. What was your households' average monthly spending on nondurable goods and services in the last three months (January 2018 to March 2018)?

Nondurable goods and services include for instance food, tobacco, alcohol, gasoline, clothing, haircuts, transportation, and other small services and nondurable goods that do not last in time. Please provide an answer in euros.

Answer: euros per month

... I do not know

4. What do you think your household's spending on nondurable goods and services will be per month in the next three months (April, May and June)? Please provide an answer in euros.
April: ............... euros
... I do not know
May:
euros
... I do not know
June:
euros
... I do not know

5. How much higher or lower do you think your household's spending on nondurable goods and services will be in the next twelve months compared to the past twelve months?

Please allocate 100 points in the table below indicating how likely the listed changes are. (Note that the points in the column should sum to 100)

Spending increases $8 \%$ or more

Spending increases $4 \%$ or more, but less than $8 \%$

Spending increases $2 \%$ or more, but less than $4 \%$

Spending increases $1 \%$ or more, but less than $2 \%$

Spending increases or decreases less than $1 \%$

Spending decreases $1 \%$ or more, but less than $2 \%$

Spending decreases $2 \%$ or more, but less than $4 \%$

\section{Points}

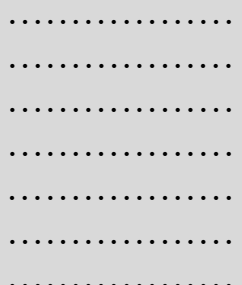


[ ] I do not know

6. How much higher or lower do you think total spending on nondurable goods and services will be for the Dutch economy (that is, all households in the Netherlands) in the next twelve months compared to the last twelve months.

Please allocate 100 points in the table below indicating how likely the listed changes are. (Note that the points in the column should sum to 100 )

Spending increases $8 \%$ or more

Spending increases $4 \%$ or more, but less than $8 \%$

Spending increases $2 \%$ or more, but less than $4 \%$

Spending increases $1 \%$ or more, but less than $2 \%$

Spending increases or decreases less than $1 \%$

Spending decreases $1 \%$ or more, but less than $2 \%$

Spending decreases $2 \%$ or more, but less than $4 \%$

Spending decreases $4 \%$ or more, but less than $8 \%$

Spending decreases $8 \%$ or more

Total (the points should sum to 100)

\section{Points}

[ ] I do not know

7. The previous question was also asked to other households in the Netherlands. We would like to know what your opinion is about what other households think will happen to total spending on nondurable goods and services in the Dutch economy in the next twelve months compared to the last twelve months.

Please allocate 100 points in the table below indicating how likely you think it is that other households in the Netherlands indicated the listed changes. (Note that the points in the column should sum to 100)

Spending increases $8 \%$ or more

Spending increases $4 \%$ or more, but less than $8 \%$

Spending increases $2 \%$ or more, but less than $4 \%$

Spending increases $1 \%$ or more, but less than $2 \%$

Spending increases or decreases less than $1 \%$

Spending decreases $1 \%$ or more, but less than $2 \%$

Spending decreases $2 \%$ or more, but less than $4 \%$

Spending decreases $4 \%$ or more, but less than $8 \%$

Spending decreases $8 \%$ or more

Total (the points should sum to 100)

\section{Points}

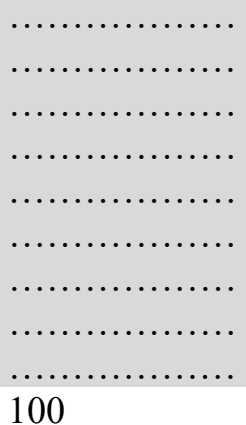

[ ] I do not know 
8. How much higher or lower do you think your household's total net income will be over the next twelve months compared to the last twelve months?

Please allocate 100 points in the table below indicating how likely the listed changes are. (Note that the points in the column should sum to 100 )

\section{Net income increases $8 \%$ or more}

Net income increases $4 \%$ or more, but less than $8 \%$

Net income increases $2 \%$ or more, but less than $4 \%$

Net income increases $1 \%$ or more, but less than $2 \%$

Net income increases or decreases less than $1 \%$

Net income decreases $1 \%$ or more, but less than $2 \%$

Net income decreases $2 \%$ or more, but less than $4 \%$

Net income decreases $4 \%$ or more, but less than $8 \%$

Net income decreases $8 \%$ or more

Total (the points should sum to 100 )

\section{Points}

[ ] I do not know

9. How much higher or lower do you think consumer prices in general in the Netherlands are now compared to twelve months earlier? Please provide a change in percentage terms. If you think prices on average decreased, please fill in a negative percentage (insert a minus sign for the number). If you think prices on average increased, please fill in a positive percentage. If you think prices on average did not change, please fill in 0 (zero).

Answer: $\quad$.............. \%

10. How much do you think consumer prices in general will change in the next twelve months in the Netherlands? Please allocate 100 points in the table below indicating how likely the listed changes are. (Note that the probabilities in the column should sum to 100 )

Consumer prices increase $8 \%$ or more

Consumer prices increase $4 \%$ or more, but less than $8 \%$

Consumer prices increase $2 \%$ or more, but less than $4 \%$

Consumer prices increase $1 \%$ or more, but less than $2 \%$

Consumer prices increase or decreases less than $1 \%$

Consumer prices decrease $1 \%$ or more, but less than $2 \%$

Consumer prices decrease $2 \%$ or more, but less than $4 \%$

Consumer prices decrease $4 \%$ or more, but less than $8 \%$

Consumer prices decrease $8 \%$ or more

Total (the points should sum to 100)

\section{Points}

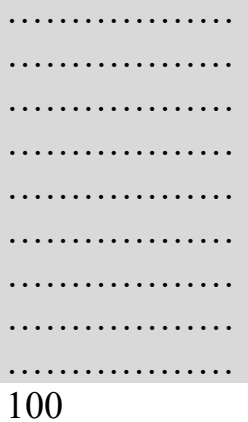


11. How much money did you have in your checking and savings accounts and in cash on the day before your last regular paycheck arrived? Please do not include fixed term deposits, stocks, bonds, mutual funds, or retirement accounts, etc.

Answer: ............... euros

... I do not know

If value: Don't Know

Please provide an estimate of the money you had in your checking and savings accounts and in cash on the day before your last regular paycheck arrived, using the categories listed below. Please do not include fixed term deposits, stocks, bonds, mutual funds, or retirement accounts, etc.

$\begin{array}{ll}\text { [ ] } & 0-249 \text { euro } \\ \text { [ ] } & 250-499 \text { euro } \\ \text { [ ] } & 500-999 \text { euro } \\ \text { [ ] } & 1,000-2,499 \text { euro } \\ \text { [ ] } & 2,500-4,999 \text { euro } \\ \text { [ ] } & 5,000-9,999 \text { euro } \\ \text { [ ] } & 10,000-14,999 \text { euro } \\ \text { [ ] } & 15,000-19,999 \text { euro } \\ \text { [ ] } & 20,000-29,999 \text { euro } \\ \text { [ ] } & 30,000-39,999 \text { euro } \\ \text { [ ] } & 40,000-49,999 \text { euro } \\ \text { [ ] } & 50,000-59,999 \text { euro } \\ \text { [ ] } & 60,000-69,999 \text { euro } \\ \text { [ ] } & 70,000-79,999 \text { euro } \\ \text { [ ] } & 80,000-89,999 \text { euro } \\ \text { [ ] } & 90,000-99,999 \text { euro } \\ \text { [ ] } & 100,000-149,999 \text { euro } \\ \text { [ ] } & 150,000-199,999 \text { euro } \\ \text { [ ] } & 200,000-249,999 \text { euro } \\ \text { [ ] } & 250,000-299,999 \text { euro } \\ \text { [ ] } & 300,000-399,999 \text { euro } \\ \text { [ ] } & 400,000-499,999 \text { euro } \\ \text { [ ] } & 500,000 \text { euro or more }\end{array}$

[ ] I do not know 
3 groups of respondents ( $\sim 500$ each, randomly selected).

a) Group A is the control group. Skip straight to "Follow-up questions" below.

b) Group B is first treatment group. They are read INFORMATION 1 below, then are asked follow-up questions below.

c) Group C is second treatment group. They are read INFORMATION 2 below, then are asked follow-up questions below.

INFORMATION 1 (for respondents in Group B): "Before we proceed, we would like to share the following information with you. In a public release available to all Dutchmen at no charge, the Dutch Statistical Office recently reported that the percent increase in consumer prices in February compared to 12 months earlier in the Netherlands was 1.2\%”.

INFORMATION 2 (for respondents in Group C): "Before we proceed, we would like to share the following information only with you and a few other households. The Dutch Statistical Office recently reported that the percent increase in consumer prices compared in February to 12 months earlier in the Netherlands was $1.2 \%$ ".

\section{Follow-up Questions:}

Instructions: (Question 14 is skipped by respondents in group A, but asked to respondents in groups B and C) 14. What percentage of Dutchmen (aged 18 and older) do you think knows this information?

Answer: $\quad$............... \%

... I do not know

15. How much higher or lower do you think your household's spending on nondurable goods and services will be in the next twelve months compared to the last twelve months?

Please provide an answer in percentage terms. If you think your household's spending on nondurable goods and services on average will decrease, please fill in a negative percentage (insert a minus sign for the number). If you think your household's spending on nondurable goods and services on average will increase, please fill in a positive percentage. If you think your household's spending on nondurable goods and services on average will not change, please fill in 0 (zero).

Answer: $\quad$.............. \%

... I do not know

16. How much higher or lower do you think total spending on nondurable goods and services will be for the Dutch economy (that is, all households in the Netherlands) in the next twelve months compared to the last twelve months.

Please provide an answer in percentage terms. If you think total spending on nondurable goods and services for the Dutch economy on average will decrease, please fill in a negative percentage (insert a minus sign for the number). If you think total spending on nondurable goods and services for the Dutch economy on average will increase, please fill in a positive percentage. If you think total spending on nondurable goods and services for the Dutch economy on average will not change, please fill in 0 (zero)
Answer:
$\%$

...I do not know

17. The previous question was also asked to other households in the Netherlands. We would like to know what your opinion is about what other households think will happen to total spending on nondurable goods and services in the Dutch economy in the next twelve months compared to the last twelve months. 
Please provide an answer in percentage terms. If you think that other households in the Netherlands believe that total spending on nondurable goods and services for the Dutch economy on average will decrease, please fill in a negative percentage (insert a minus sign for the number). If you think that other households in the Netherlands believe that total spending on nondurable goods and services for the Dutch economy on average will increase, please fill in a positive percentage. If you think that other households in the Netherlands believe that total spending on nondurable goods and services for the Dutch economy on average will not change, please fill in 0 (zero).

\section{Answer: $\quad$.............. \%}

...I do not know

18. How much higher or lower do you think your household's total net income will be over the next twelve months compared to the last twelve months? Please provide an answer in percentage terms.

Please provide an answer in percentage terms. If you think that your household's total net income will decrease, please fill in a negative percentage (insert a minus sign for the number). If you think that your household's total net income will increase, please fill in a positive percentage. If you think that your household's total net income will not change, please fill in 0 (zero).

Answer: $\quad \ldots \ldots \ldots \ldots \ldots \ldots$
$\ldots$ I do not know

19. How much do you think consumer prices in general will change in the next twelve months in the Netherlands?

Please provide an answer in percentage terms. If you think consumer prices on average will decrease, please fill in a negative percentage (insert a minus sign for the number). If you think consumer prices on average will increase, please fill in a positive percentage. If you think consumer prices on average will not change, please fill in 0 (zero).

Answer: $\quad \ldots \ldots \ldots \ldots \ldots \%$

20. Finally, the last three questions. Suppose you had $€ 100$ in a savings account and the interest rate was $2 \%$ per year. After 5 years, how much do you think you would have in the account if you left the money to grow: more than $€ 102$, exactly $€ 102$, less than $€ 102$

[ ] More than $€ 102$

[ ] Exactly $€ 102$

[ ] Less than $€ 102$

[ ] I do not know

21. Imagine that the interest rate on your savings account was $1 \%$ per year and inflation was $2 \%$ per year. After 1 year, how much would you be able to buy with the money in this account: more than today; exactly the same, less than today?

[ ] More than today

[ ] Exactly the same

[ ] Less than today

[ ] I do not know

22. Do you think that the following statement is 'true' or 'false'? Buying a company stock usually provides a safer return than a stock mutual fund.

[ ] True

[ ] False

[ ] I do not know 


\section{WAVE 2: QUESTIONNAIRE (to be fielded in May 2018)}

1. How much did your household spend on purchases of durable goods in the month April 2018 ?

Durable goods are goods that last in time, including for instance cars, electronics, kitchen appliances, furniture, house maintenance, jewelries, etc. (please exclude purchases of houses, apartments, etc.). Please provide an answer in euros.

Answer:................ euros

... I did not buy any durables... I do not know

2. What do you think your household's spending on purchases of durable goods will be per month in the next two months (May and June)? Please provide an answer in euros.

May: ................. euros

... I do not have plans to buy durables in this month

... I do not know

June: euros

... I do not have plans to buy durables in this month

... I do not know

3. What was your households' spending on nondurable goods and services in the month April 2018?

Nondurable goods and services include for instance food, tobacco, alcohol, gasoline, clothing, haircuts, transportation, and other small services and nondurable goods that do not last in time. Please provide an answer in euros.

April:

euros

... I do not know

4. What do you think your household's spending on nondurable goods and services will be per month in the next two months (May and June)? Please provide an answer in euros.

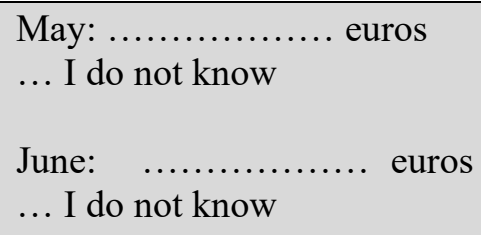

15. How much higher or lower do you think your household's spending on nondurable goods and services will be in the next twelve months compared to the last twelve months?

Please provide an answer in percentage terms. If you think your household's spending on nondurable goods and services on average will decrease, please fill in a negative percentage (insert a minus sign for the number). If you think your household's spending on nondurable goods and services on average will increase, please fill in a positive percentage. If you think your household's spending on nondurable goods and services on average will not change, please fill in 0 (zero). 
Answer:

16. How much higher or lower do you think total spending on nondurable goods and services will be for the Dutch economy (that is, all households in the Netherlands) in the next twelve months compared to the last twelve months.

Please provide an answer in percentage terms. If you think total spending on nondurable goods and services for the Dutch economy on average will decrease, please fill in a negative percentage (insert a minus sign for the number). If you think total spending on nondurable goods and services for the Dutch economy on average will increase, please fill in a positive percentage. If you think total spending on nondurable goods and services for the Dutch economy on average will not change, please fill in 0 (zero)

\section{Answer: $\quad$...............\%}

...I do not know

17. The previous question was also asked to other households in the Netherlands. We would like to know what your opinion is about what other households think will happen to total spending on nondurable goods and services in the Dutch economy in the next twelve months compared to the last twelve months.

Please provide an answer in percentage terms. If you think that other households in the Netherlands believe that total spending on nondurable goods and services for the Dutch economy on average will decrease, please fill in a negative percentage (insert a minus sign for the number). If you think that other households in the Netherlands believe that total spending on nondurable goods and services for the Dutch economy on average will increase, please fill in a positive percentage. If you think that other households in the Netherlands believe that total spending on nondurable goods and services for the Dutch economy on average will not change, please fill in 0 (zero).

\section{Answer: $\quad$...............\%} ...I do not know

18. How much higher or lower do you think your household's total net income will be over the next twelve months compared to the last twelve months? Please provide an answer in percentage terms.

Please provide an answer in percentage terms. If you think that your household's total net income will decrease, please fill in a negative percentage (insert a minus sign for the number). If you think that your household's total net income will increase, please fill in a positive percentage. If you think that your household's total net income will not change, please fill in 0 (zero).

Answer: $\quad \ldots \ldots \ldots \ldots \ldots \ldots$

... I do not know

8. Now we are interested in how likely you think your income will change. How much higher or lower do you think your household's total net income will be over the next twelve months compared to the last twelve months?

Please allocate 100 points in the table below indicating how likely the listed changes are. (Note that the points in the column should sum to 100)

\section{Points}

................. 
Net income increases more than $4 \%$, but less than $8 \%$

Net income increases more than $2 \%$, but less than $4 \%$

Net income increases more than $1 \%$, but less than $2 \%$

Net income increases or decreases no more than $1 \%$

Net income decreases more than $1 \%$, but less than $2 \%$

Net income decreases more than $2 \%$, but less than $4 \%$

Net income decreases more than $4 \%$, but less than $8 \%$

Net income decreases more than $8 \%$

Total (the points should sum to 100)

[ ] I do not know

9. How much higher or lower do you think consumer prices in general in the Netherlands are now compared to twelve months earlier? Please provide a change in percentage terms. If you think prices on average decreased, please fill in a negative percentage (insert a minus sign for the number). If you think prices on average increased, please fill in a positive percentage. If you think prices on average did not change, please fill in zero.

Answer:

$\ldots \ldots \ldots \ldots \ldots$

19. How much do you think consumer prices in general will change in the next twelve months in the Netherlands?

Please provide an answer in percentage terms. If you think consumer prices on average will decrease, please fill in a negative percentage (insert a minus sign for the number). If you think consumer prices on average will increase, please fill in a positive percentage. If you think consumer prices on average will not change, please fill in 0 (zero).

Answer: $\quad$.............. \%

10. Now we are interested in how likely you think consumer prices will change. How much do you think consumer prices in general will change in the next twelve months in the Netherlands? Please allocate 100 points in the table below indicating how likely the listed changes are. (Note that the probabilities in the column should sum to 100)

Consumer prices increase more than $10 \%$

Consumer prices increases more than $5 \%$, but less than $10 \%$

Consumer prices increases more than $3 \%$, but less than $5 \%$

Consumer prices increases more than $1 \%$, but less than $3 \%$

Consumer prices increases or decreases no more than $1 \%$

Consumer prices decreases more than $1 \%$, but less than $3 \%$

Consumer prices decreases more than $3 \%$, but less than $5 \%$

Consumer prices decreases more than $5 \%$, but less than $10 \%$

Consumer prices decreases more than $10 \%$

Total (the points should sum to 100):

\section{Points}

................

(n..............

(...............

n..............

n...............

.................

n...............

.................

100 


\section{WAVE 3: QUESTIONNAIRE (to be fielded in June 2018)}

1. How much did your household spend on purchases of durable goods in the month May 2018?

Durable goods are goods that last in time, including for instance cars, electronics, kitchen appliances, furniture, house maintenance, jewelries, etc. (please exclude purchases of houses, apartments, etc.). Please provide an answer in euros.

Answer:................ euros

... I did not buy any durables... I do not know

2. What do you think your household's spending on purchases of durable goods will be in June? Please provide an answer in euros.

June: euros

... I do not have plans to buy durables in this month

... I do not know

5. What was your households' spending on nondurable goods and services in the month May 2018 ?

Nondurable goods and services include for instance food, tobacco, alcohol, gasoline, clothing, haircuts, transportation, and other small services and nondurable goods that do not last in time. Please provide an answer in euros.

May: ............. euros

... I do not know

6. What do you think your household's spending on nondurable goods and services will be in June? Please provide an answer in euros.

June: $\quad \ldots \ldots \ldots \ldots \ldots$ euros

... I do not know

20. How much higher or lower do you think your household's spending on nondurable goods and services will be in the next twelve months compared to the last twelve months?

Please provide an answer in percentage terms. If you think your household's spending on nondurable goods and services on average will decrease, please fill in a negative percentage (insert a minus sign for the number). If you think your household's spending on nondurable goods and services on average will increase, please fill in a positive percentage. If you think your household's spending on nondurable goods and services on average will not change, please fill in 0 (zero).

Answer: $\quad$...............\%

... I do not know 
21. How much higher or lower do you think total spending on nondurable goods and services will be for the Dutch economy (that is, all households in the Netherlands) in the next twelve months compared to the last twelve months.

Please provide an answer in percentage terms. If you think total spending on nondurable goods and services for the Dutch economy on average will decrease, please fill in a negative percentage (insert a minus sign for the number). If you think total spending on nondurable goods and services for the Dutch economy on average will increase, please fill in a positive percentage. If you think total spending on nondurable goods and services for the Dutch economy on average will not change, please fill in 0 (zero)
Answer:
$\%$

...I do not know

22. The previous question was also asked to other households in the Netherlands. We would like to know what your opinion is about what other households think will happen to total spending on nondurable goods and services in the Dutch economy in the next twelve months compared to the last twelve months.

Please provide an answer in percentage terms. If you think that other households in the Netherlands believe that total spending on nondurable goods and services for the Dutch economy on average will decrease, please fill in a negative percentage (insert a minus sign for the number). If you think that other households in the Netherlands believe that total spending on nondurable goods and services for the Dutch economy on average will increase, please fill in a positive percentage. If you think that other households in the Netherlands believe that total spending on nondurable goods and services for the Dutch economy on average will not change, please fill in 0 (zero).

Answer: $\quad$............... \%

...I do not know

23. How much higher or lower do you think your household's total net income will be over the next twelve months compared to the last twelve months? Please provide an answer in percentage terms.

Please provide an answer in percentage terms. If you think that your household's total net income will decrease, please fill in a negative percentage (insert a minus sign for the number). If you think that your household's total net income will increase, please fill in a positive percentage. If you think that your household's total net income will not change, please fill in 0 (zero).

Answer: $\quad \ldots \ldots \ldots \ldots \ldots \%$

... I do not know

10. Now we are interested in how likely you think your income will change. How much higher or lower do you think your household's total net income will be over the next twelve months compared to the last twelve months?

Please allocate 100 points in the table below indicating how likely the listed changes are. (Note that the points in the column should sum to 100)

Net income increases more than $8 \%$

Net income increases more than $4 \%$, but less than $8 \%$

Net income increases more than $2 \%$, but less than $4 \%$

Net income increases more than $1 \%$, but less than $2 \%$

Net income increases or decreases no more than $1 \%$

Net income decreases more than $1 \%$, but less than $2 \%$

\section{Points}

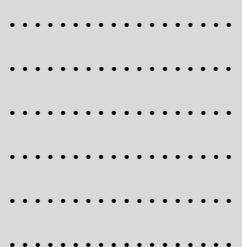


Net income decreases more than $2 \%$, but less than $4 \%$

Net income decreases more than $4 \%$, but less than $8 \%$

Net income decreases more than $8 \%$

Total (the points should sum to 100)

..................

[ ] I do not know

11. How much higher or lower do you think consumer prices in general in the Netherlands are now compared to twelve months earlier? Please provide a change in percentage terms. If you think prices on average decreased, please fill in a negative percentage (insert a minus sign for the number). If you think prices on average increased, please fill in a positive percentage. If you think prices on average did not change, please fill in zero.

Answer: $\quad$............... \%

24. How much do you think consumer prices in general will change in the next twelve months in the Netherlands?

Please provide an answer in percentage terms. If you think consumer prices on average will decrease, please fill in a negative percentage (insert a minus sign for the number). If you think consumer prices on average will increase, please fill in a positive percentage. If you think consumer prices on average will not change, please fill in 0 (zero).

Answer: $\quad \ldots \ldots \ldots \ldots \ldots \ldots \%$

11. Now we are interested in how likely you think consumer prices will change. How much do you think consumer prices in general will change in the next twelve months in the Netherlands? Please allocate 100 points in the table below indicating how likely the listed changes are. (Note that the probabilities in the column should sum to 100)

Consumer prices increase more than $10 \%$

Consumer prices increases more than $5 \%$, but less than $10 \%$

Consumer prices increases more than $3 \%$, but less than $5 \%$

Consumer prices increases more than $1 \%$, but less than $3 \%$

Consumer prices increases or decreases no more than $1 \%$

Consumer prices decreases more than $1 \%$, but less than $3 \%$

Consumer prices decreases more than $3 \%$, but less than $5 \%$

Consumer prices decreases more than $5 \%$, but less than $10 \%$

Consumer prices decreases more than $10 \%$

Total (the points should sum to 100):

\section{Points}

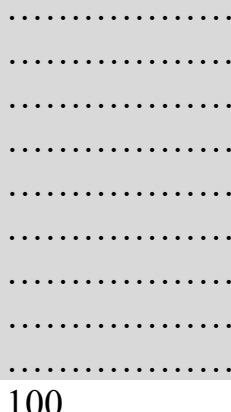

100 


\section{WAVE 4: QUESTIONNAIRE (to be fielded in July 2018)}

1. How much did your household spend on purchases of durable goods in the month June 2018 ?

Durable goods are goods that last in time, including for instance cars, electronics, kitchen appliances, furniture, house maintenance, jewelries, etc. (please exclude purchases of houses, apartments, etc.). Please provide an answer in euros.

Answer:................ euros

... I did not buy any durables

... I do not know

3. What was your households' spending on nondurable goods and services in the month June 2018 ?

Nondurable goods and services include for instance food, tobacco, alcohol, gasoline, clothing, haircuts, transportation, and other small services and nondurable goods that do not last in time. Please provide an answer in euros.

Answer:

euros

... I do not know

15. How much higher or lower do you think your household's spending on nondurable goods and services will be in the next twelve months compared to the last twelve months?

Please provide an answer in percentage terms. If you think your household's spending on nondurable goods and services on average will decrease, please fill in a negative percentage (insert a minus sign for the number). If you think your household's spending on nondurable goods and services on average will increase, please fill in a positive percentage. If you think your household's spending on nondurable goods and services on average will not change, please fill in 0 (zero).

Answer: $\quad$............... \%

... I do not know

16. How much higher or lower do you think total spending on nondurable goods and services will be for the Dutch economy (that is, all households in the Netherlands) in the next twelve months compared to the last twelve months.

Please provide an answer in percentage terms. If you think total spending on nondurable goods and services for the Dutch economy on average will decrease, please fill in a negative percentage (insert a minus sign for the number). If you think total spending on nondurable goods and services for the Dutch economy on average will increase, please fill in a positive percentage. If you think total spending on nondurable goods and services for the Dutch economy on average will not change, please fill in 0 (zero)

Answer: $\quad \ldots \ldots \ldots \ldots \ldots \%$

...I do not know 
17. The previous question was also asked to other households in the Netherlands. We would like to know what your opinion is about what other households think will happen to total spending on nondurable goods and services in the Dutch economy in the next twelve months compared to the last twelve months.

Please provide an answer in percentage terms. If you think that other households in the Netherlands believe that total spending on nondurable goods and services for the Dutch economy on average will decrease, please fill in a negative percentage (insert a minus sign for the number). If you think that other households in the Netherlands believe that total spending on nondurable goods and services for the Dutch economy on average will increase, please fill in a positive percentage. If you think that other households in the Netherlands believe that total spending on nondurable goods and services for the Dutch economy on average will not change, please fill in 0 (zero).

\section{Answer: $\quad$............... \%}

...I do not know

18. How much higher or lower do you think your household's total net income will be over the next twelve months compared to the last twelve months? Please provide an answer in percentage terms.

Please provide an answer in percentage terms. If you think that your household's total net income will decrease, please fill in a negative percentage (insert a minus sign for the number). If you think that your household's total net income will increase, please fill in a positive percentage. If you think that your household's total net income will not change, please fill in 0 (zero).

Answer: $\quad \ldots \ldots \ldots \ldots \ldots \ldots$
$\ldots$ I do not know

8. Now we are interested in how likely you think your income will change. How much higher or lower do you think your household's total net income will be over the next twelve months compared to the last twelve months?

Please allocate 100 points in the table below indicating how likely the listed changes are. (Note that the points in the column should sum to 100)

Net income increases more than $8 \%$

Net income increases more than $4 \%$, but less than $8 \%$

Net income increases more than $2 \%$, but less than $4 \%$

Net income increases more than $1 \%$, but less than $2 \%$

Net income increases or decreases no more than $1 \%$

Net income decreases more than $1 \%$, but less than $2 \%$

Net income decreases more than $2 \%$, but less than $4 \%$

Net income decreases more than $4 \%$, but less than $8 \%$

Net income decreases more than $8 \%$

Total (the points should sum to 100 )

\section{Points}

[] I do not know

9. How much higher or lower do you think consumer prices in general in the Netherlands are now compared to twelve months earlier? Please provide a change in percentage terms. If you think prices on average decreased, please fill in a negative percentage (insert a minus sign for the number). If you think prices on average increased, please fill in a positive percentage. If you think prices on average did not change, please fill in zero. 
19. How much do you think consumer prices in general will change in the next twelve months in the Netherlands?

Please provide an answer in percentage terms. If you think consumer prices on average will decrease, please fill in a negative percentage (insert a minus sign for the number). If you think consumer prices on average will increase, please fill in a positive percentage. If you think consumer prices on average will not change, please fill in 0 (zero).

Answer: $\quad \ldots \ldots \ldots \ldots \ldots \%$

10. Now we are interested in how likely you think consumer prices will change. How much do you think consumer prices in general will change in the next twelve months in the Netherlands? Please allocate 100 points in the table below indicating how likely the listed changes are. (Note that the probabilities in the column should sum to 100)

Consumer prices increase more than $10 \%$

Consumer prices increases more than $5 \%$, but less than $10 \%$

Consumer prices increases more than $3 \%$, but less than $5 \%$

Consumer prices increases more than $1 \%$, but less than 3\%

Consumer prices increases or decreases no more than $1 \%$

Consumer prices decreases more than $1 \%$, but less than $3 \%$

Consumer prices decreases more than $3 \%$, but less than $5 \%$

Consumer prices decreases more than $5 \%$, but less than $10 \%$

Consumer prices decreases more than $10 \%$

Total (the points should sum to 100):

\section{Points}

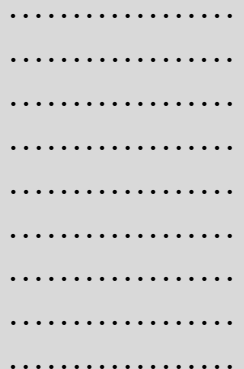

..... 100 